\title{
Title: Li and Turner Modified model for Predicting Liquid Loading in Gas Wells
}

\author{
Princewill Maduabuchi Ikpeka ${ }^{1} \cdot$ Michael Onyinyechukwu Okolo ${ }^{1}$
}

Received: 22 August 2018 / Accepted: 2 November 2018 / Published online: 27 November 2018

(c) The Author(s) 2018

\begin{abstract}
Background Liquid loading of gas wells causes production difficulty and reduces ultimate recovery from these wells. Several authors proposed different models to predict the onset of liquid loading in gas wells, but the results from the models often show discrepancies. Turner's et al. (J Pet Technol, 1969) critical model was developed based on the assumption that the droplet is a sphere and remains spherical all through the entire wellbore. On the other hand, Li's model was developed based on the assumption the liquid droplets are flat in shape and remains same all through the wellbore. However, it is a well-known fact that the droplet alternates between spherical and flat during production operation. Invariably, the Turner's model and the Li's model would not be able to predict correctly the critical rate required to lift that droplet which is because the droplet deformation was not taken into account during the development of the models.

Materials and methods In this work, a new improved model is developed and incorporated into Ms-Excel program to predict liquid loading in gas wells. In the new model, a deformation coefficient " $C$ " is introduced to cater for the deformation of the liquid droplet along the wellbore and in turn be able to predict correctly the critical rate when the droplet varies from the spherical shape to the flat shape.

Results Results from the analysis carried out revealed 35\% error on from Turner's model, $26 \%$ error on Li's model, whereas the new model yielded $20 \%$ error.
\end{abstract}

Conclusion The new developed software and model proved to be more accurate in predicting onset of liquid loading.

Keywords Predicting liquid loading in gas wells $\cdot$ Liquid loading $\cdot$ Gas production $\cdot$ Ms-Excel program $\cdot$ New improved model $\cdot$ Turner model $\cdot \mathrm{Li}$ model $\cdot$ Gas wells $\cdot$ Production challenges in gas wells

\section{List of symbols}

$\rho_{1}$

$\rho_{\mathrm{g}} \quad$ Gas density, $\mathrm{lbm} / \mathrm{ft}^{3}$

$\sigma \quad$ Interfacial tension, dynes/cm

$P \quad$ Pressure, $\mathrm{lbf} / \mathrm{ft}^{2}$

$D_{\mathrm{H}} \quad$ Hydraulic diameter, $\mathrm{ft}$

A Cross-sectional area of conduit, $\mathrm{ft}^{2}$

$T \quad$ Temperature, ${ }^{\circ} \mathrm{R}$

$z \quad$ Gas compressibility factor

$S_{\mathrm{g}} \quad$ Specific gravity of gas

$S_{\mathrm{O}} \quad$ Specific gravity of produced oil

$S_{\mathrm{w}} \quad$ Specific gravity of produced water

Princewill Maduabuchi Ikpeka

Princewill.ikpeka@futo.edu.ng

Michael Onyinyechukwu Okolo michaelokolo62@yahoo.com

1 Department of Petroleum Engineering, Federal University of Technology, Owerri, Nigeria

$\begin{array}{ll}S_{\mathrm{s}} & \text { Specific gravity of produced solid } \\ Q_{\mathrm{g}} & \text { Gas production rate, Mscf/D } \\ Q_{\mathrm{o}} & \text { Oil production rate, B/D } \\ Q_{\mathrm{w}} & \text { Water production rate, B/D } \\ Q_{\mathrm{s}} & \text { Solids production rate, } \mathrm{ft}^{3} / \text { day } \\ p_{\mathrm{hf}} & \text { Wellhead flowing pressure, psia } \\ Q_{\mathrm{gm}} & \text { Minimum gas flow rate required to transport } \\ & \text { liquid drops, Mscf/D } \\ E_{\mathrm{km}} & \text { Minimum kinetic energy required to transport } \\ & \text { liquid drops, lbf-ft/ft } \\ V_{\text {crit-S }} & \text { Critical velocity Luan's model } \\ V_{\text {crit-W }} & \text { Critical velocity Wang's model } \\ V_{\text {crit-L }} & \text { Critical velocity Li's model } \\ V_{\text {crit-N }} & \text { Critical velocity Nosseir's model } \\ V_{\text {crit-T }} & \text { Critical velocity Turner's model } \\ V_{\text {crit-C }} & \text { Critical velocity Coleman's model } \\ V_{\text {crit-new }} & \text { Critical velocity new model } \\ \text { We } & \text { Webers number } \\ \text { Re } & \text { Reynolds number }\end{array}$


$\rho \quad$ Density, lb/cu ft

$v \quad$ Flow velocity, ft/s

\section{Introduction}

\section{Background of study}

Natural gas can be simply defined as a naturally occurring mixture of light hydrocarbons consisting mainly of methane but also contains varying amounts of heavier alkanes and other impurities such as carbon dioxide, hydrogen sulphide, helium, nitrogen and water. Natural gas exists in reservoir in different thermodynamic states; as dry gas, wet gas and as retrograde condensate. Although natural gas consumption in Nigeria is quite small compared to some countries such as the US, natural gas production is faced with variety of challenges one of which is the issue of liquid loading. Liquid loading, in a nutshell can be defined as the accumulation of liquid or water in the wellbore due to insufficient gas velocity to evacuate the liquid phase which is co-produced with the gas resulting in reduction or complete cessation of gas production. These usually occur due to depletion of the reservoir pressure and at this stage the gas produced is unable to lift the liquid produced alongside it, to the surface and at such causing an accumulation of the liquid in the wellbore, and overtime as the liquid accumulates it builds up a high hydrostatic pressure in the wellbore thereby preventing further production of gas. Liquid loading leads to the premature death of a gas well which becomes a financial loss to the operating company.

The liquid content in the gas come from a variety of sources either in liquid form or in vapour form depending on the prevailing well conditions, some sources are; free water present in the formation produced alongside the gas, water condensate and hydrocarbon condensate which enter the well as vapour but while travelling up the tubing condenses, in a case where the well completion is an open one, water or other liquid can flow from other zones into the well bore, in a case where there is an aquifer below the gas zone.

Liquid loading is not always easy to predict and recognize because a thorough diagnostic analysis of the well data needs to be done but accurate prediction of the problem is vitally important for taking timely measures to solve the problem. There are some symptoms also which can help predict a gas well which is under attack such as the onset of liquid slugs at the surface of the well, increasing difference between the tubing and casing pressures with time, sharp changes in gradient on a flowing pressure survey and sharp drops in production decline curve.

In a bid to predict the onset of liquid loading early which has been identified as the key step in salvaging the liquid loading problem, various investigators over the years have come up with models and methods to predict liquid loading in gas wells, the pioneer been Turner et al. (1969) subsequently other predictions came up most based on the foundation principle of Turner et al. (1969). Some of these models were better, some worse, but the various models used for the predictions had their merits and demerits. The Turner model and other models used in predicting liquid loading are included in subsequent sections.

After detection of liquid accumulation in the well, few solutions have been discovered to solve the problem of liquid loading in gas wells over the years and they have proved really helpful. These include foaming of the liquid water which can enable the gas to lift water from the well, the use of reduced tubing diameter and the heating the wellbore to the prevent further condensation, the use of plunger lift which is an intermittent artificial lift method which uses the energy of the gas reservoir to produce the liquid collected at the bottom of the hole, the use of gas lift method which involves injection of gas into the well from another source in other to increase gas production the use of the beam pumping which is a method commonly used in the oil industry to solve liquid loading in wells loaded with liquid hydrocarbon.

\section{Statement of problem}

From the above definition of liquid loading, it is clear that it is problematic to gas wells, ranging from decreasing the gas well production rate to completely preventing gas production from the well. However, if liquid loading can be predicted accurately and on time a suitable solution can be put together to combat it. This prediction in question is the primary aim of this study and research, due to the fact that the predicting methods at various points and times show various discrepancies, coming up or developing a better prediction mechanism will go a long way in saving maybe hundreds of petroleum gas wells which would have shut down prematurely due to liquid loading.

\section{Aim of the study}

This study aims at developing a new model for predicting critical velocity rate for gas wells building on the premise of Turner et al. (1969) and Li et al. (2001). The model developed would then be incorporated into an Ms-Excel-based program.

\section{Significance of study}

As was earlier stated, that early detection of liquid loading in gas wells helps the production team prepare a suitable technique and method to tackle the problem at its early stage before it aggravates. On the completion of this study, 
software which when provided with the necessary data has the ability to predict liquid loading status of a given well will be developed.

\section{Materials and methods}

This research work was done on a three-phase scale:

1. Gathering of the various prediction model, evaluating their errors and choosing the better one.

2. Discover the merit and demerit of the chosen model and improve on it.

3. Finally build it into an excel platform for easy usage.

\section{Predicting liquid loading}

Liquid load-up in gas wells is not always obvious; therefore, a thorough diagnostic analysis of well data needs to be carried out to adequately predict the rate at which liquids will accumulate in the well. Although this subject has been studied extensively but the results from previous investigators and the most commonly applied model in the industry still has a high degree of inaccuracy, especially in predicting the minimum gas flow rate required to prevent liquid loading into the well bore (Adesina et al. 2013).

\section{Turner's model}

For the removal of gas well liquids, Turner et al. (1969) proposed two physical models: (1) the continuous film model (2) and entrained drop movement model.

The continuous film model Turner et al. (1969) were of the opinion that since liquid film accumulation on the walls of a conduit during two-phase gas/liquid flow is inevitable due to the impingement of entrained liquid drops and the condensation of vapours. He also suggested that the annular liquid film must keep moving upwards along the conduit walls to keep a gas well from loading up, and in the same vain the minimum gas flow rate necessary to accomplish this is of primary importance in the prediction of liquid loading. The analysis technique used involves describing the profile of the velocity of a liquid film moving upward on the inside of a tube. The major shortcoming of this model was its inability to clearly define between the adequate and inadequate rates when it was analysed with field data.

Entrained drop movement model (spherical shape droplet model) The existence of liquid drops in the gas stream presents a different problem in fluid mechanics, namely, that of determining the minimum rate of gas flow that will lift the drops out of the well (Turner et al. 1969). In a bid to do this,
Turner et al. proposed a model to calculate the minimum gas flow velocity necessary to remove liquid drops from a gas well which is based on the sole principle of a freely falling particle in a fluid medium (by a transformation of coordinates, a drop of liquid being transported by a moving gas stream becomes a free falling particle and the same general equations apply as shown in Fig. 1). The minimum gas flow velocity necessary to remove liquid drop is given by the following equation:

$V_{\text {crit-Tunadjusted }}=1.593 \frac{\sigma^{1 / 4}\left(\rho_{\mathrm{L}}-\rho_{\mathrm{g}}\right)^{1 / 4}}{\rho_{\mathrm{g}}^{1 / 2}}$.

Turner et al. (1969) discovered that the drop model prediction in most cases was too low and he blamed this on the values of critical weber number and drag coefficient used in the development of the model and also on the fact that the mathematical development predicts stagnation velocity, which must be exceeded by some finite quantity to guarantee removal of the largest droplets. Analysis of the Turner's data reveals that the total contribution of these factors requires an upward adjustment of approximately 20\%. Mapping Turner's calculated model against actual test data (as shown in Fig. 2) reveals large discrepancies at lower flowrates; hence adjusted droplet model is given by the following equation to accommodate these discrepancies:

$V_{\text {crit- }}=1.92 \frac{\sigma^{1 / 4}\left(\rho_{\mathrm{L}}-\rho_{\mathrm{g}}\right)^{1 / 4}}{\rho_{\mathrm{g}}^{1 / 2}}$,

$q_{\text {crit-T }}=\frac{3060 P V_{\text {crit- } \mathrm{T}} A}{T z}$.

\section{Coleman model}

Coleman et al. (1991) made use of the Turner model but validated with field data of lower reservoir and wellhead

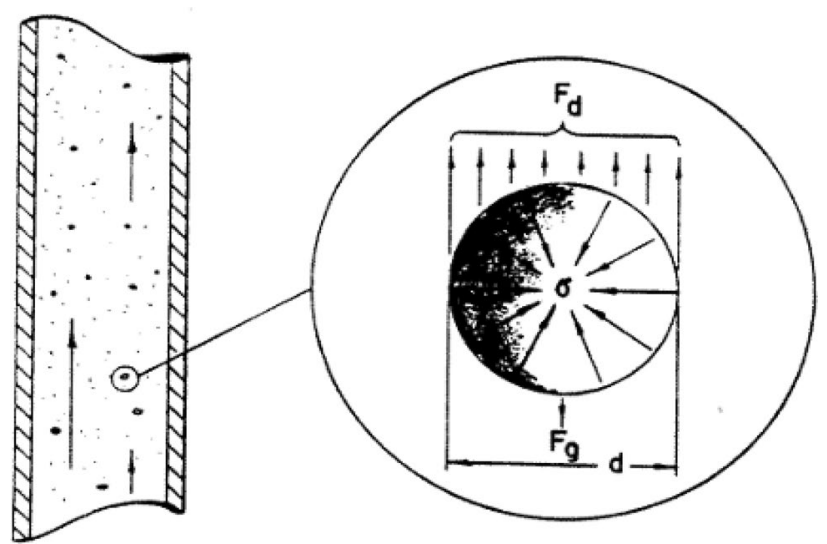

Fig. 1 Entrained droplet movement (Turner et al. 1969)

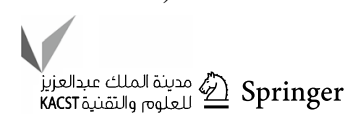




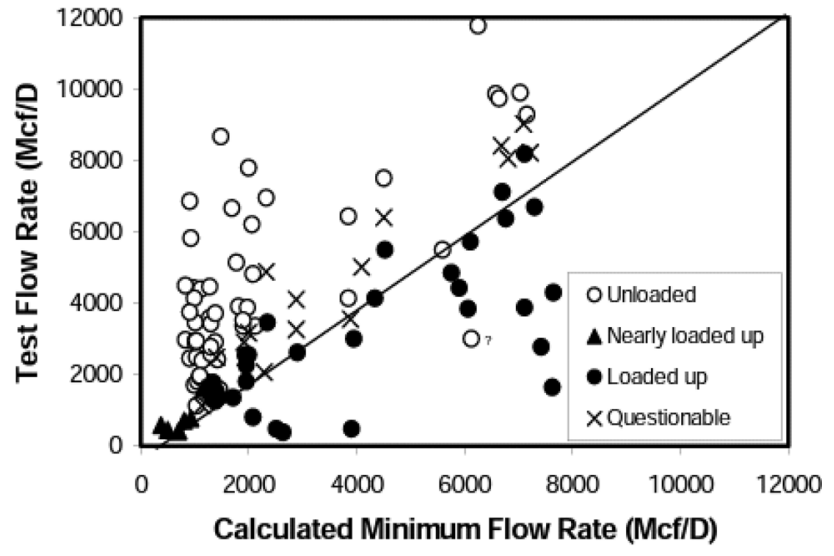

Fig. 2 Turner et al. model-calculated minimum flow rates mapped against the test flow rates (Guo et al. 2006)

flowing pressure all below approximately 500 psia. Coleman et al. (1991) discovered that a better prediction could be achieved without a $20 \%$ upward adjustment to fit field data with the following expressions:

$V_{\text {crit-C }}=1.593\left[\frac{\sigma\left(\rho_{\mathrm{L}}-\rho_{\mathrm{g}}\right)}{\rho_{\mathrm{g}}^{2}}\right]^{\frac{1}{4}}$,

$q_{\text {crit-C }}=\frac{3060 P V_{\text {crit-C }} A}{T z}$.

\section{Li's model (flat-shaped droplet model)}

Li et al. (2001) in their research posited that Turner and Coleman's models did not consider deformation of the free falling liquid droplet in a gas medium, and furthermore, contended that as a liquid droplet is entrained in a high velocity gas stream, a pressure difference exists between the fore and aft portions of the droplet leading to its deformation and its shape changes from spherical to convex bean with unequal sides (flat) as shown in Fig. 3.

Spherical liquid droplets have a smaller efficient area and need a higher terminal velocity and critical rate to lift them to the surface. However, flat-shaped droplets have a more efficient area and are easier to be carried to the wellhead. This lead to the formulation of the following expression:

$V_{\text {crit-L }}=\frac{0.7241 \sigma^{1 / 4}\left(\rho_{1}-\rho_{\mathrm{g}}\right)^{1 / 4}}{\rho_{\mathrm{g}}^{1 / 2}}$,

$q_{\text {crit-L }}=\frac{3060 P V_{\text {crit-L }} A}{T z}$.

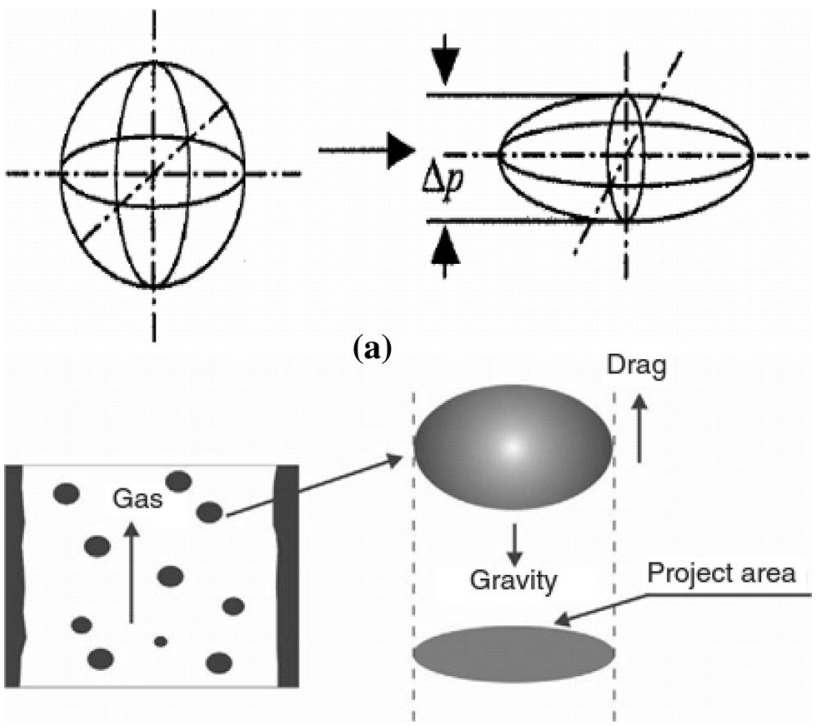

(b)

Fig. 3 a Flat-shaped droplet model. b Shape of entrained droplet moving in high velocity gas (Li et al. 2001)

\section{Nosseir's model}

Nosseir et al. (2000) focused his study mainly on the impact of flow regime and changes in flow conditions on gas well loading. Their work was similar to that of Turner but the difference between the both was that Turner did not consider the effect of flow regime on the drag coefficient (used in the derivation stage), and thereby making use of the same drag coefficient (0.44) for laminar, transient and turbulent flows. Nosseir derived the critical flow equations by assuming drag coefficient value of 0.44 for Reynolds number $(R e) 2 \times 10^{5}$ to $10^{4}$ and for $R e$ value greater than $10^{6}$ he took the drag coefficient value to be 0.2 . Representation of the critical velocity equation by Nosseir's model is summarized as:

$V_{\text {crit-N }}=1.938\left[\frac{\sigma\left(\rho_{1}-\rho_{\mathrm{g}}\right)}{\rho_{\mathrm{g}}^{2}}\right]^{1 / 4}$,

$q_{\text {crit- } \mathrm{N}}=\frac{3060 P V_{\text {crit-N }} A}{T z}$.

\section{Disk-shaped droplet model}

Some authors consider that the four dimensionless numbers, Reynolds, Mortan, Eotvos, and Weber (especially the first two parameters), are always used to characterize the shape of bubbles or droplets moving in a surrounding fluid or continuous phase (Hinze 1955; Youngren and Acrivos 1976; Acharya et al. 1977). Wang and Liu (2007) were of the opinion that for typical oilfield condition, the Reynolds number 
ranges from $10^{4}$ to $10^{6}$, and the Morton number for low viscosity liquid in gas wells is possibly between $10^{-10}$ and $10^{-12}$. For the given ranges of the dimensionless numbers, they found that most of the entrained droplets in gas well are disk shaped. Similar to flat-shaped droplets proposed by $\mathrm{Li}$ et al. (2001), the disk-shaped droplets have a more efficient area and are more easily carried to the wellhead. For the disk-shaped droplets, the drag coefficient $C_{\mathrm{d}}$ is close 1.17 . Wang's expressions can be summarized as follows:

$$
\begin{aligned}
V_{\text {crit-W }} & =0.5213\left[\frac{\sigma\left(\rho_{1}-\rho_{\mathrm{g}}\right)}{\rho_{\mathrm{g}}^{2}}\right]^{1 / 4}, \\
q_{\text {crit-W }} & =\frac{3060 P V_{\text {crit-W}} A}{T z} .
\end{aligned}
$$

\section{Guohua and Shunli's model}

In this work, Guohua and Shunli (2012) carried out reviews on various models spotting their merit and shortcomings but paid much attention to the Turner's model (spherical shaped droplet model) and Li's model (flat shaped droplet model). $q_{\text {crit-S }}=\frac{3060 P V_{\text {crit-S }} A}{T z}$,

\section{Guo's model}

Guo et al. (2006) were of the opinion that although various investigators have suggested several methods of predicting liquid loading but the results from these methods often show discrepancies and are not easy to use due to the difficulties with prediction of the bottom hole pressure in multiphase flow.

Guo et al. (2006) formulated a closed form analytical equation for predicting the minimum gas flow rate for the continual removal of liquid from the gas well. He did this by substituting the Turner et al.'s entrained drop movement model (for predicting minimum gas velocity for the continual removal of liquid from the gas well) into the kinetic energy equation to obtain the minimum kinetic energy the gas must possess in other to keep the well unloaded. The final stage of his work was to apply the minimum kinetic energy equation to the four phase mist flow model in gas wells to obtain the equation for predicting the minimum gas flow rate which can be solved using numerical method (Newton Raphson) or the go seek function built in the MS Excel. Below is a summary of Guo's model:

$$
\begin{gathered}
b\left[6.46 \times 10^{-13} \frac{S_{g} T Q_{\mathrm{gm}}^{2}}{A^{2} E_{\mathrm{km}}}-p_{\mathrm{hf}}\right]+\frac{1-2 b m}{2} \ln \left|\frac{\left[6.46 \times 10^{-13} \frac{S_{g} T Q_{\mathrm{gm}}^{2}}{A^{2} E_{\mathrm{km}}}+m\right]^{2}+n \mid}{\left(P_{\mathrm{hf}}+m\right)^{2}+n}\right| \\
\quad-\frac{m+\frac{b}{c} n-b m^{2}}{\sqrt{n}}\left[\tan ^{-1}\left[\frac{6.46 \times 10^{-13} \frac{S_{g} T Q_{\mathrm{gm}}^{2}}{A^{2} E_{\mathrm{km}}}+m}{\sqrt{n}}\right]-\tan ^{-1}\left[\frac{P_{\mathrm{hf}+m}}{\sqrt{n}}\right]\right]=a\left(1+d^{2} e\right) L,
\end{gathered}
$$

Using experimental results from Awolusi (2005) and Wei et al. (2007) (both though did different experiments came out with the same conclusion), Guohua and Shunli (2012) discovered that the Turner's model overestimated the probability of the occurrence of liquid loading in gas wells and Li's model underestimated after a plot of critical gas flow rate was done against flow tubing pressure, for measured flow rates and calculated flow rates from Turner's and Li's model.

Guohua and Shunli (2012) came up with a dimensionless parameter of loss factor $S$ which he introduced to his new model and using data from Coleman's work. This loss factor $S$ ranges from zero to unity (the larger it is, the closer the calculated results are to Turner's model and if zero the new model matches Li's model). Luan compared results from his work with Turner and Li and discovered that his was more accurate. Summary of Luan model given below:

$V_{\text {crit-S }}=V_{\text {crit-L }}+0.83 \times\left(V_{\text {crit-T }}-V_{\text {crit-L }}\right)$,

$$
a=\frac{15.33 S_{\mathrm{S}} Q_{\mathrm{S}}+86.07 S_{\mathrm{w}} Q_{\mathrm{w}}+86.07 S_{\mathrm{O}} Q_{\mathrm{O}}+0.01879 S_{\mathrm{g}} Q_{\mathrm{g}}}{T Q_{\mathrm{g}}} \cos (\theta),
$$

$$
b=n=\frac{c^{2} e}{\left(1+d^{2} e\right)^{2}} \frac{0.2456 Q_{\mathrm{s}}+1.379 Q_{\mathrm{w}}+1.379 Q_{\mathrm{o}}}{T Q_{\mathrm{g}}},
$$$$
c=\frac{4.712 \times 10^{-5} T Q_{\mathrm{g}}}{A},
$$

$$
d=\frac{Q_{\mathrm{s}}+5.615\left(Q_{\mathrm{w}}+Q_{\mathrm{O}}\right)}{86400 A},
$$

$$
e=\frac{f}{2 g D_{\mathrm{H}} \cos (\theta)},
$$


$f=\left[\frac{1}{1.74-2 \log \left[\frac{2 \varepsilon}{D_{\mathrm{H}}}\right]}\right]^{2}$,

$m=\frac{c d e}{1+d^{2} e}$,

$n=\frac{c^{2} e}{\left(1+d^{2} e\right)^{2}}$

\section{Nodal analysis}

Nodal analysis can be used to estimate the onset of liquid loading in gas wells with more accuracy since it considers the complete flow path of fluids from reservoir to wellhead (Nallaparaju et al. 2012). In nodal analysis, the system is divided into two subsystems at a certain location called nodal point. The first subsystem takes into account inflow from reservoir to nodal point (IPR), while the other subsystem considers outflow from the nodal point to the surface (TPR). The curves formed by this relation on the pressure-rate graph are called the inflow curve and the outflow curve, respectively. The point where these two curves intersect denotes the optimum operating point where pressure and flow rate are equal for both of the curves. Turner's critical rate prediction in relation with the IPR and TPR curves can be used to predict liquid loading.

In a study carried out by Nallaparaju et al. 2012, we observe that Turner's critical rate model was plotted with IPR and TPR for a Well with a given initial static reservoir pressure of $3281 \mathrm{psi}$ and Tubing head pressure of $1500 \mathrm{psi}$ as shown in Fig. 4 above. The point at which the Turner's curve meets with the IPR curve represent the minimum flowrate to prevent liquid loading (10MMSCFD), whereas the optimum operating flowrate for the well is around 75MMSCFD. The

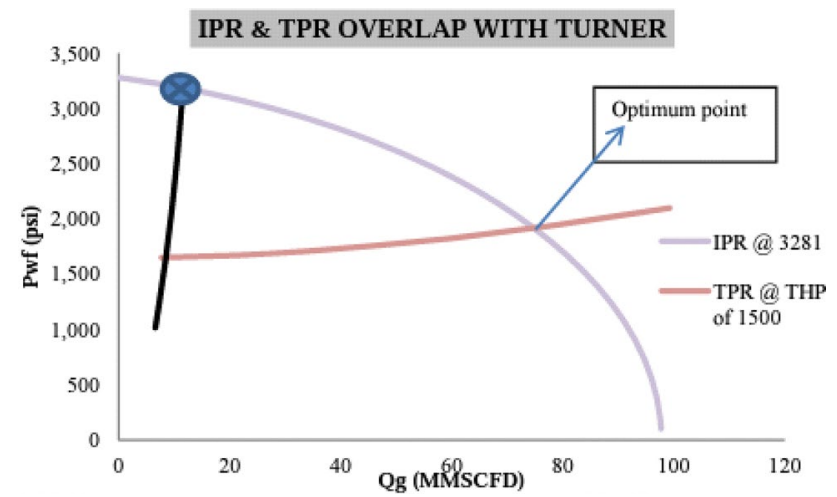

Fig. 4 IPR and TPR overlap with Turner (Nallaparaju et al. 2012) farther the operating point from the minimum flowrate, the lower the tendency for liquid loading to occur.

\section{Zhou model}

Turner et al. (1969) entrained droplet model is the most popular model in predicting liquid loading in gas wells (Zhou and Yuan 2009). However, there were still quite a few wells that could not be covered even after a $20 \%$ upward adjustment (Turner et al. 1969). By studying the droplet model and liquid film mechanisms, Zhou came up with a new model.

In his work, he studied the force balance on a single liquid droplet, which are the upward drag force, $F_{\mathrm{D}}$; the upward buoyant force, $F_{\mathrm{B}}$; and downward gravity force, $F_{\mathrm{G}}$, which

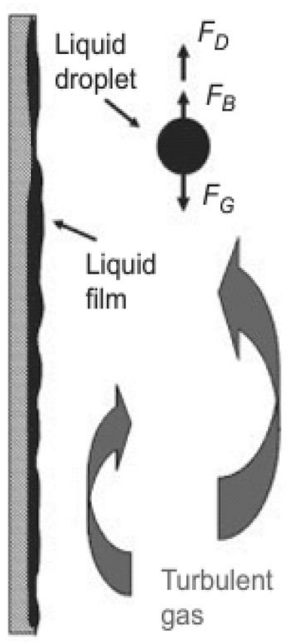

(a)
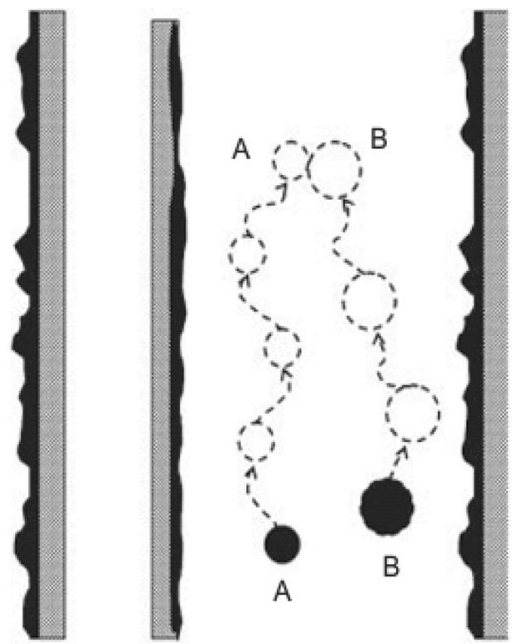

(b)
Fig. 5 Encountering two liquid droplets in turbulent gas stream

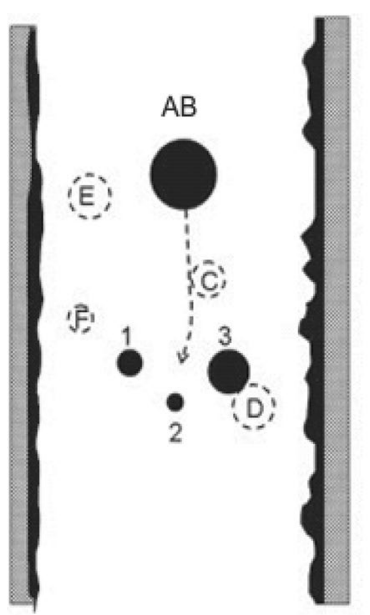

(a)

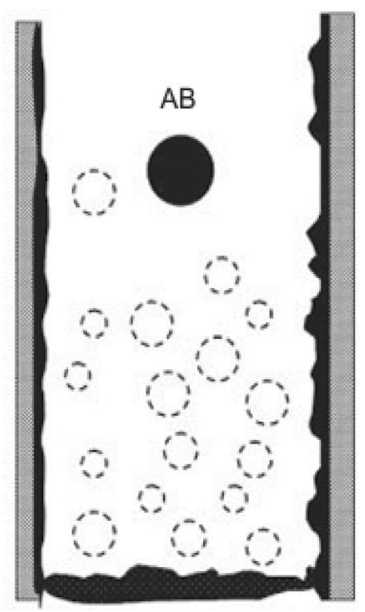

(b)
Fig. 6 Liquid loading when liquid droplet number reaches a threshold value (Zhou and Yuan 2009) 
for unloading to be possible and for the droplets to move upwards $\left(F_{\mathrm{D}}+F_{\mathrm{B}}\right)$ must be greater than $F_{\mathrm{G}}$ otherwise the droplet will accelerate downwards. The Turner et al. (1969) droplet model was based on the balance of these forces $\left(\mathrm{F}_{\mathrm{D}}+\mathrm{F}_{\mathrm{B}}=\mathrm{F}_{\mathrm{G}}\right)$.

Zhou argued that Turner et al. (1969) based his model on force balance on a single liquid droplet, but which in a gas stream, there are more than one as shown above (droplets $\mathrm{A}$ and B in Fig. 5). And further argued that if a turbulent flow existed in the gas stream, due to the irregularity of the flow droplets will encounter each other and coalesces will occur as in Fig. 6 below forming a droplet $\mathrm{AB}(\mathrm{A}+\mathrm{B})$. This newly formed droplet in a situation the gas stream does not have enough energy to lift the droplet it starts falling and may scatter into smaller droplets 1,2,3 and the cycle goes on and on for similar larger droplets and these leads to an accumulation of liquid down hole.

Zhou and Yuan (2009) were of the opinion that if there are more liquid droplets in the gas stream, the chance of the process of liquid droplet encountering, coalescing, falling and scattering increases (Fig. 6). As the number of liquid droplets in a gas stream, called liquid droplet concentration increases to a threshold value $\beta$, the process of droplets encountering, coalescing, falling and scattering will continue and bring those liquid droplets down to the well bottom. The liquid droplet concentration in a gas stream is defined by

$$
\begin{aligned}
H_{1} & =\frac{\text { Liquid superficial velocity }}{\text { Gas superficial velocity+liquid superficial velocity }} \\
& =\frac{V_{\mathrm{sl}}}{V_{\mathrm{sg}}+V_{\mathrm{sl}}} .
\end{aligned}
$$

Zhou and Yuan (2009) concluded that if liquid droplet concentration is above the threshold value, then the new model can be used but below the threshold value Turners model is used. Summary of Zhou model:

$V_{\text {crit-Z }}=V_{\text {crit- } \mathrm{T}}=1.593 \frac{\left[\sigma\left(\rho_{l}-\rho_{\mathrm{g}}\right)\right]^{1 / 4}}{\rho_{\mathrm{g}}^{1 / 2}}$ for $\quad H_{l} \leqslant \beta$,

$V_{\text {crit-Z }}=V_{\text {crit-T }}+\ln \frac{H_{1}}{\beta}+\alpha$ for $H_{1}>\beta$,

$Q\left(\frac{M c f}{D}\right)_{\text {crit-Z }}=\frac{3060 P V_{\text {crit-Z }} A}{T Z}$

\section{Experimental works on liquid loading}

A series of experiments have been designed by Awolusi (2005) and Wei et al. (2007) which were done separately.

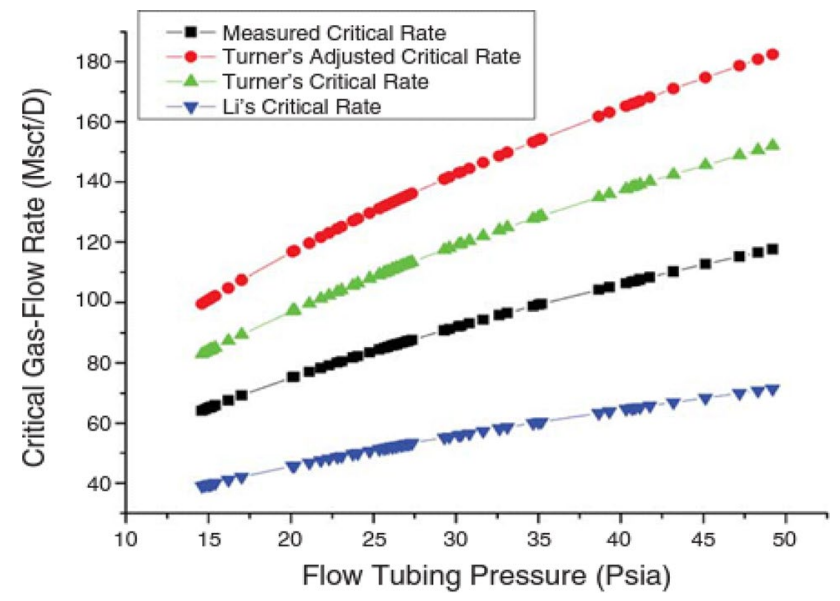

Fig. 7 Critical rate against flow tubing pressure (Awolusi 2005)

The primary aim of their work was to investigate and evaluate discrepancies in the previous works on critical gas velocities required to keep liquid from accumulating. Which resulted to the discovery that Turner model prediction was high compared to the actual observed critical rate, while Li's model prediction was low compared to the actual observed critical rate as can be seen in Fig. 7 below.

\section{Model development}

As was earlier stated at the beginning of this chapter, we are aimed at developing a new model which can be used to calculate the critical rate and in turn predict the onset of liquid loading in gas wells.

This new model was developed by combining the Turner critical rate model and the Li's critical rate model.

\section{Theory}

$V_{\text {crit-T }}=1.593\left[\frac{\sigma\left(\rho_{1}-\rho_{\mathrm{g}}\right)}{\rho_{\mathrm{g}}^{2}}\right]^{\frac{1}{4}}$.

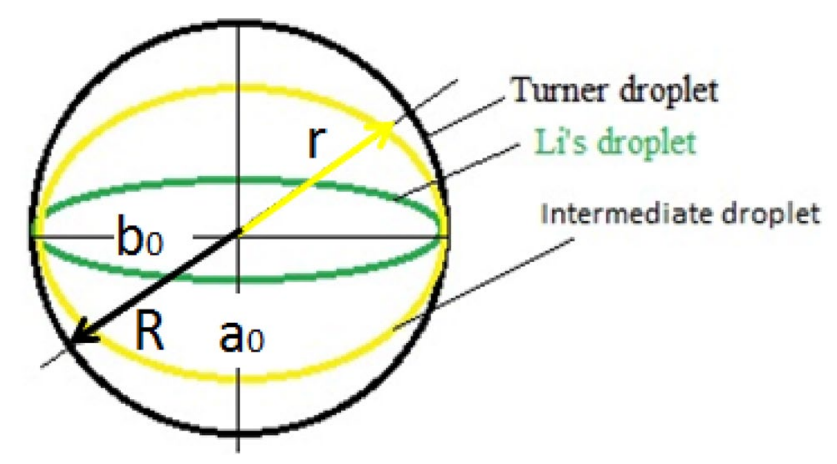

Fig. 8 Droplet shapes 
Turner's critical model given above was developed based on the assumption that the droplet is a sphere and remains spherical all through the entire wellbore,

$V_{\text {crit-L }}=\frac{0.7241 \sigma^{1 / 4}\left(\rho_{1}-\rho_{\mathrm{g}}\right)^{1 / 4}}{\rho_{\mathrm{g}}^{1 / 2}}$.

On the other hand, Li's model above was developed based on the assumption that the liquid droplets are flat in shape and remains same all through the wellbore. Having considered the two above droplet shape, in a case where the droplet is neither spherical nor flat as can be observed in Fig. 8 invariably the Turner's model and the Li's model would not be able to predict correctly the critical rate required to lift that droplet which is because the droplet deformation was not taken into account during the development of the models. As the droplet travel up the wellbore they tend to deform and can take different shapes at different points in the well. For simplicity sake, the only droplet shapes consider in this paper are droplet shapes ranging from the spherical shape to the flat shape (Fig. 9).

In the new model, a deformation coefficient $\mathrm{C}$ is introduced to cater for the deformation of the liquid droplet along the wellbore and in turn be able to predict correctly the critical rate when the droplet varies from the spherical shape to the flat shape.

\section{New model development}

New critical velocity model

$=\mathrm{Li}^{\prime} \mathrm{s}$ critical velocity model + deformation coefficient $\times$ (Turner's critical velocity model - Li's critical velocity model),
$V_{\text {crit-new }}=V_{\text {crit-L }}+C \times\left(V_{\text {crit-T }}-V_{\text {crit-L }}\right)$.

The deformation coefficient used in this work is adapted from Kelbaliyev and Ceylan (2007). Detailed derivation of the deformation coefficient can be found in "Appendix 5".

$C=\frac{a_{0}}{b_{0}}=\frac{R\left(1-\lambda_{\mathrm{v}} W e\right)}{R\left(1+\lambda_{\mathrm{v}} / 2 W e\right)}$.

Using the experimental data from Raymond and Rosant (2000), $\lambda_{\mathrm{v}}$ is estimated as:

$\lambda_{\mathrm{v}}=\frac{1}{12}\left(1-\frac{3 W e}{25 \operatorname{Re}}\right)$.

Weber's number can be obtained from

$W e=\frac{\rho \times v^{2} l}{\sigma}$,

Table 1 Summary of all assumptions used to prepare critical velocity rate for our new model

\begin{tabular}{lll}
\hline Parameters & Value & Unit \\
\hline Condensate surface tension & 20 & Dynes/cm \\
Water surface tension & 60 & Dynes/cm \\
Condensate density & 45 & $\mathrm{Lb} / \mathrm{cu} \mathrm{ft}$ \\
Water density & 67 & $\mathrm{Lb} / \mathrm{cu} \mathrm{ft}$ \\
Gas specific gravity & 0.6 & \\
Wellhead temperature & 580 & Rankine \\
\hline
\end{tabular}

The condensate surface tension and density are used to calculate only when condensate is produced along with the gas

The water surface tension and density are used to calculate when only water is produced or when both water and condensate are produced along with the gas

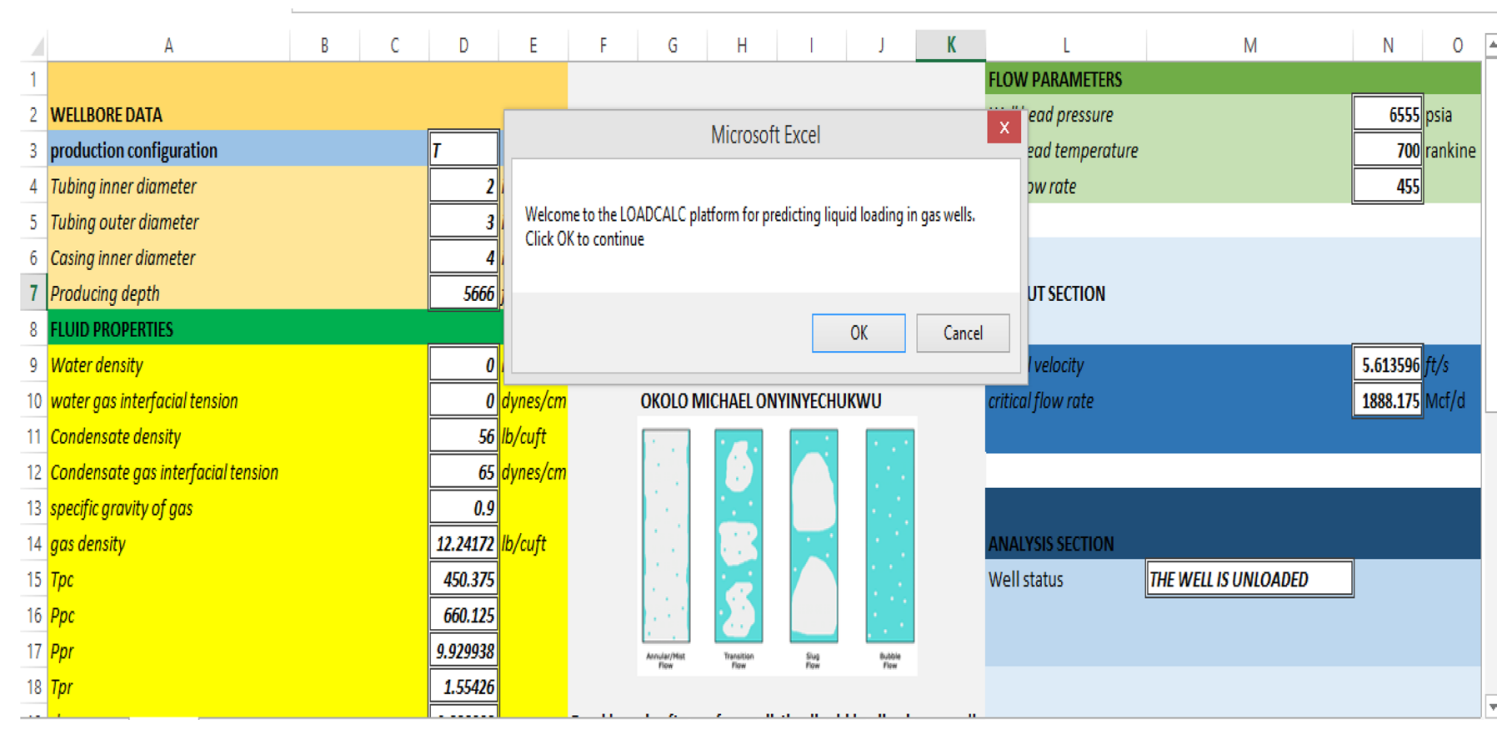

Fig. 9 User interface for LOADCALC Software 
whereas Reynolds number is obtained from

$R e=\frac{Q D_{\mathrm{H}}}{v A}$.

Computing the values of Table 1 into Eqs. (35) and (36), the value of $C$ was calculated to be:

$C=2.261921523$

$V_{\text {crit-new }}=V_{\text {crit-L }}+2.261921523 \times\left(V_{\text {crit-T }}-V_{\text {crit-L }}\right)$,

$V_{\text {crit-new }}=\frac{0.7241 \sigma^{1 / 4}\left(\rho_{1}-\rho_{\mathrm{g}}\right)^{1 / 4}}{\rho_{\mathrm{g}}^{1 / 2}}+2.261921523$

$\times\left[\frac{1.593 \sigma^{1 / 4}\left(\rho_{1}-\rho_{\mathrm{g}}\right)^{1 / 4}}{\rho_{\mathrm{g}}^{1 / 2}}-\frac{0.7241 \sigma^{1 / 4}\left(\rho_{1}-\rho_{\mathrm{g}}\right)^{1 / 4}}{\rho_{\mathrm{g}}^{1 / 2}}\right]$,

$q_{\text {crit-new }}=\frac{3060 P V_{\text {crit-new }} A}{T z}=$ Critical flow rate.

The derivation of the Turner and Li models is shown in "Appendix 1".

\section{Software development}

After the new model was developed, the new model and other related correlations were converted to computer codes and built into an excel platform leading to the development of a new software LOADCALC. The computer codes used for the development of LOADCALC are shown in appendix D.

\section{LOADCALC features}

LOADCALC software is colourful software and it is user friendly and consists of various sections;
a. Wellbore data section
b. Fluid properties section
c. Introductory section
d. Flow parameter section
e. Output section
f. Analysis section

\section{Results}

In other to be able to compute the critical rate using the new model and also compare with the critical rate from Turner and $\mathrm{Li}$, the Turner et al. (1969) data on liquid loaded wells were utilised. Turner published important parameters which influence critical liquid loading rate calculation such as producing depth, wellhead pressures, liquid gas rate, fluid properties, tubing inner/outer diameter, casing diameter and also

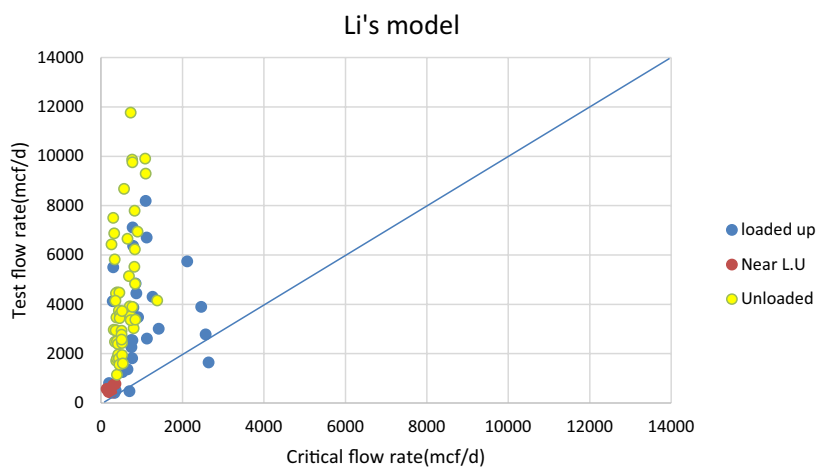

Fig. 10 Crossplot of test flowrate against critical flowrate using Li's model

information on the well flow rate and status (loaded up, near load up and unloaded) at time of test was also included in the database. These data are shown in "Appendix 3".

\section{Assumptions}

All assumptions are summarized in Table 1 below;

\section{Calculated parameters}

Due to the large amount of database, the calculations for the below parameters are done using an excel sheet.

Parameters
a. Gas density
b. Production area
c. Compressibility factor

The results for the calculated parameters, formulas, correlations used in calculation are all stated and outlined in "Appendix 2".

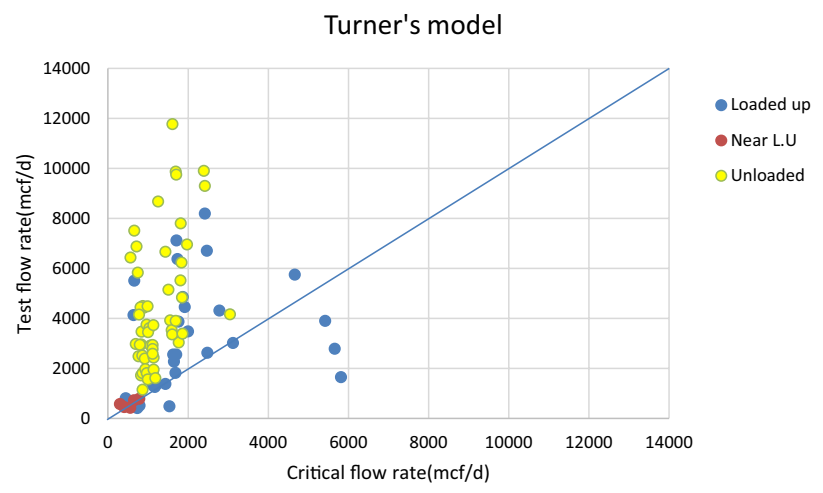

Fig. 11 Crossplot of test flowrate against critical flowrate using Turner model 


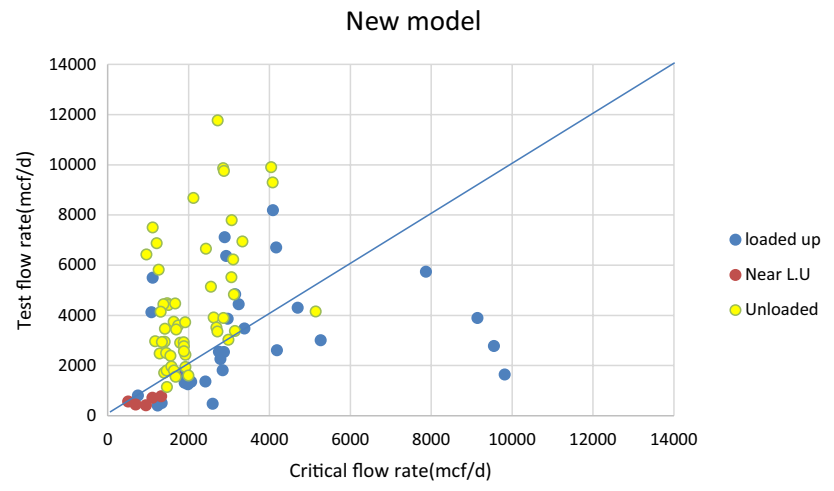

Fig. 12 Crossplot of test flowrate against critical flowrate using New model

\section{Critical velocity results}

Using the production data from the 105 gas wells, assumed parameters and calculated parameter, an excel sheet was used to compute the critical rate for.

- The new critical velocity model.

- The Turner critical velocity model.

- The Li's critical velocity model.

The results from the different critical velocity models are tabulated in "Appendix 2".

When the measured flow rate from the different gas wells was plotted against the critical flow rates from the different models in the above table, the following figures were obtained, Figs. 10, 11, 12.

\section{Discussion}

The above figures are constructed in such a way that if a well's actual test flow rate equals its critical flow rate for liquid removal, the point will plot on the diagonal, so therefore for critical velocity model to be correct, the wells that are tested at conditions near load-up should plot near this diagonal. Wells that unload easily during a test should plot above the diagonal and those that do not unload should plot below the line. The ability of a given analytical model to achieve this data separation is a measure of its validity.

As can be seen from Figs. 10, 11 and 12 above the most data separation is achieved by the new model in Fig. 12 and in turn provides a better prediction.

Li's model as can be seen in Fig. 10 was not able to separate the loaded wells from the unloaded wells, almost all the points plotted above the diagonal line, suggesting that all the wells are unloaded which is not correct compared to the well status obtained from the different wells during test.

Turner model as can be seen in Fig. 11 predicted better than Li but majority of the loaded wells still plotted in the unloaded region above the diagonal line.

From Fig. 12, it can be observed that the new model prediction was quite better than Turner and Li due to the fact that most of the loaded wells plotted in the loaded region, most of the unloaded wells plotted in the unloaded region and the near load up wells plotted close to the diagonal.

\section{Software test}

To test the efficiency of the LOADCALC software, the well data from a loaded well, an unloaded well and a well which is near load up was collected and feed in the software.

The summary of the production data from the three different wells is shown in Table 2.
Table 2 Summary of the production data from the three different wells

\begin{tabular}{llll}
\hline Well status & Loaded up & Near load up & Unloaded \\
\hline Producing depth (ft) & 2250 & 6770 & 6180 \\
Wellhead pressure (psia) & 210 & 450 & 1117 \\
Wellhead temperature (rankine) & 580 & 580 & 580 \\
Tubing ID (in.) & 0 & 1.995 & 0 \\
Tubing OD (in.) & 2.375 & 0 & 2.878 \\
Casing ID (in.) & 6.276 & 0 & 6.184 \\
Production configuration & Annular & Tubular & Annular \\
Specific gravity & 0.6 & 0.6 & 0.6 \\
Water density (lb/cu ft) & 67 & 0 & 0 \\
Water surface tension (dynes/cm) & 60 & 0 & 0 \\
Condensate density (lb/cu ft) & 0 & 45 & 45 \\
Condensate surface tension (dynes/cm) & 0 & 20 & 20 \\
Test flow rate (mcf/days) & 470 & 442 & 5513 \\
Critical flow rate(mcf/days) & 2593.59 & 685.20 & 2928.38 \\
\hline
\end{tabular}




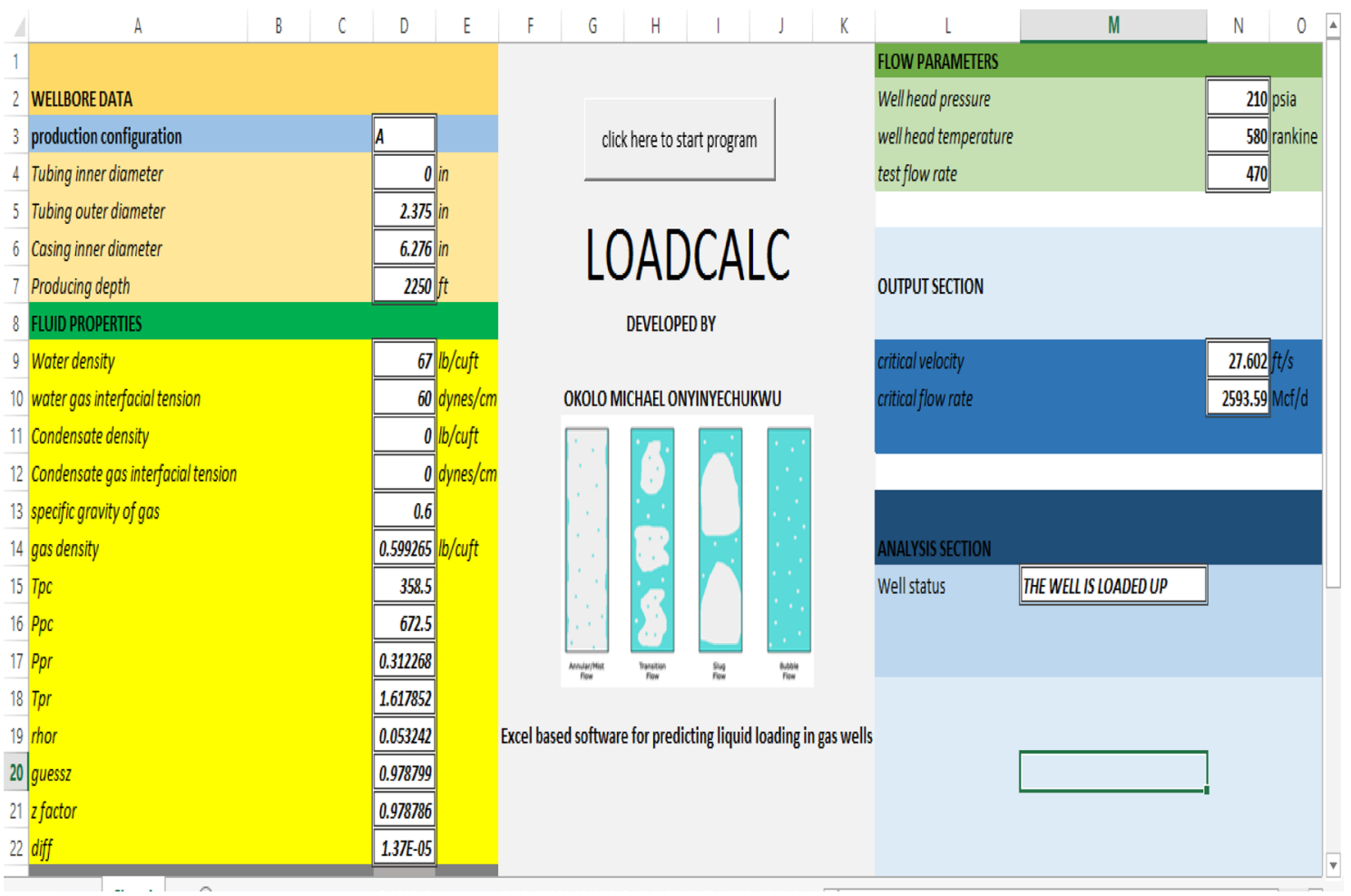

Fig. 13 LOADCALC software interface showing loaded up test

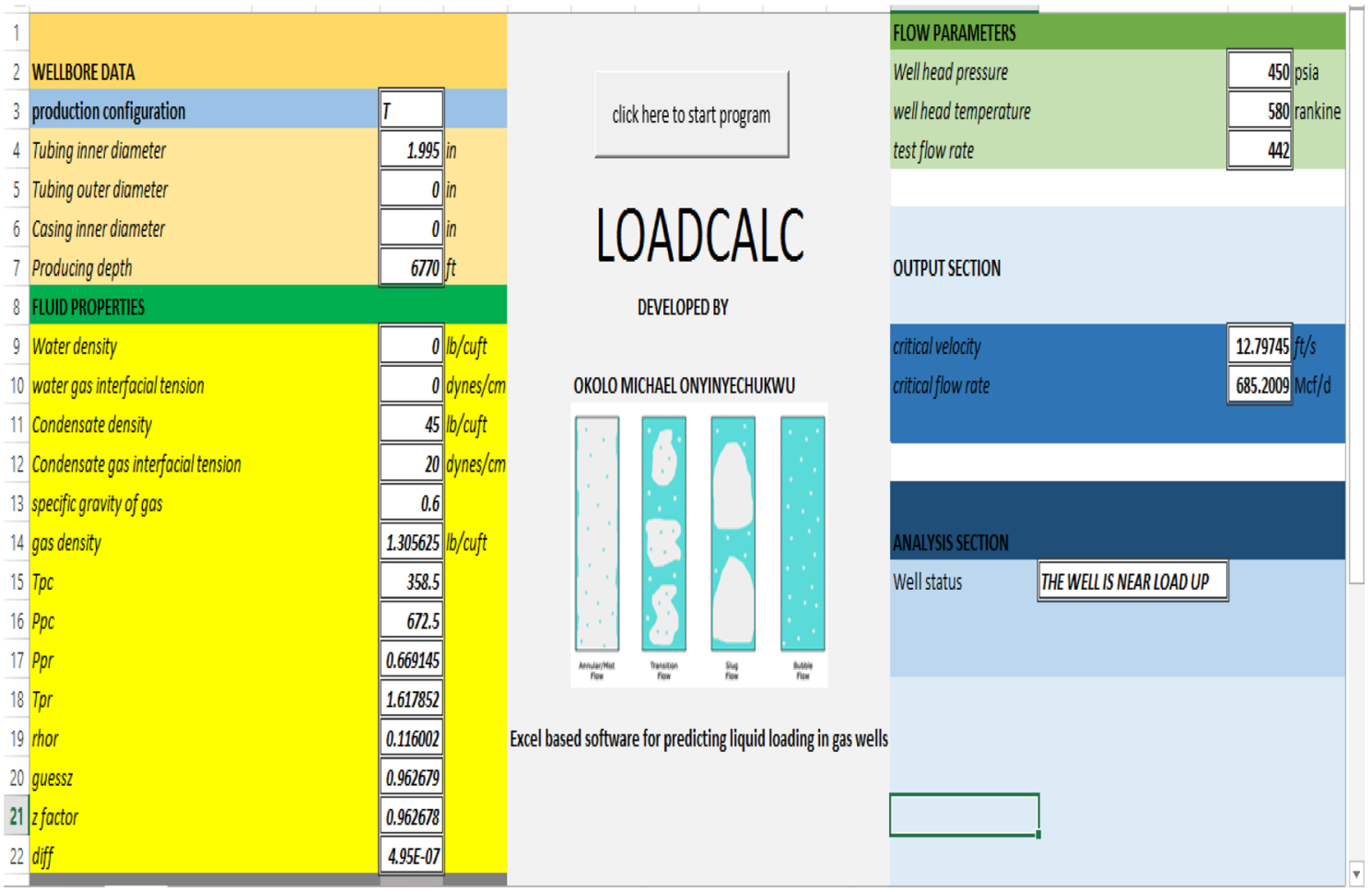

Fig. 14 LOADCALC software interface showing near load up test 


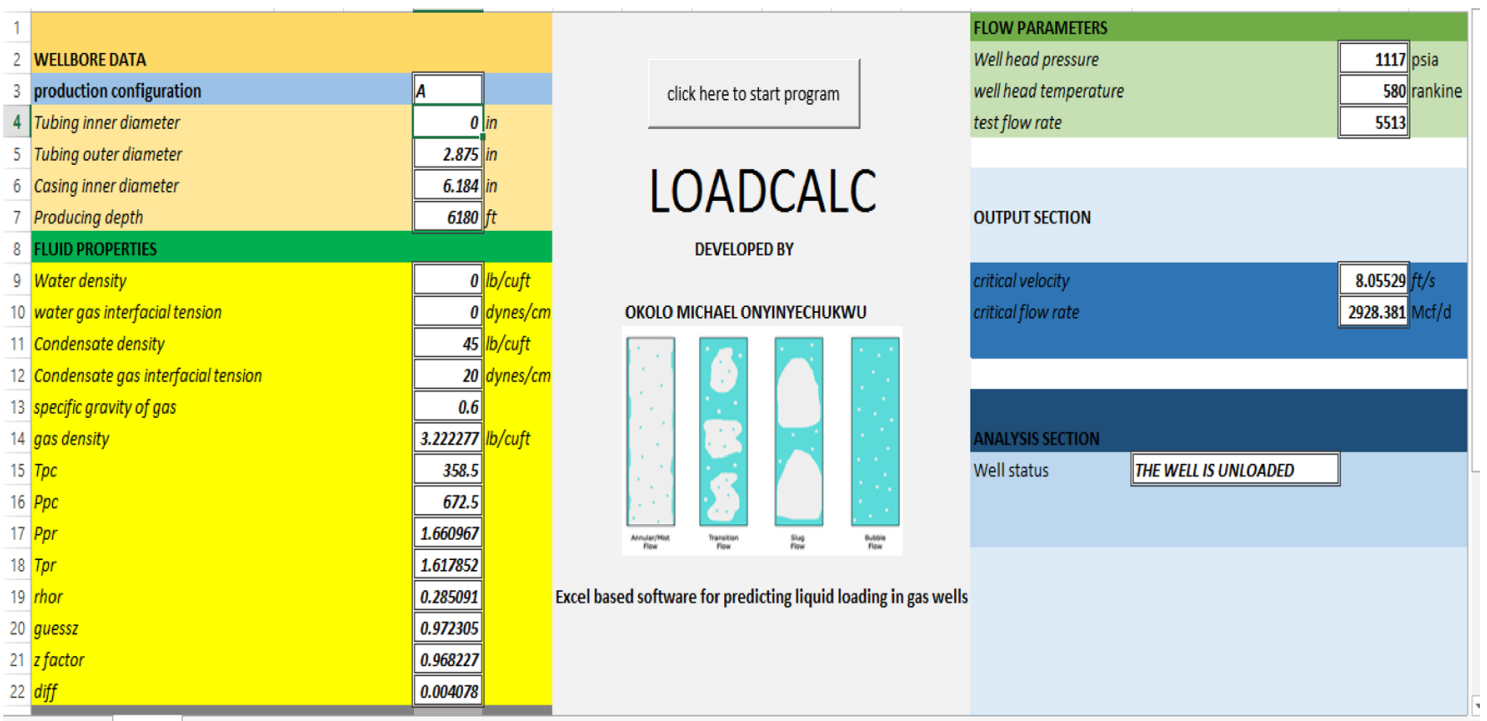

Fig. 15 LOADCALC software interface showing unloaded test

\section{Loaded up test}

See Fig. 13.

\subsection{Near load up test}

See Fig. 14.

\section{Unloaded test}

See Fig. 15.

As can be observed from the test figures above the results from the software matches with the test result in Table 2 .

\section{Conclusion}

This paper presents a new empirical model that calculates the critical velocity and flowrate for low-pressure gas wells by taking into account droplet deformation coefficient. The new model is derived from a modification of Turner's model and Li's model. The Turner's critical model above was developed based on the assumption that the droplet is a sphere and remains spherical all through the entire wellbore On the other hand, Li's model above was developed based on the assumption the liquid droplets are flat in shape and remains same all through the wellbore. By applying the deformation and elasticity theory, a dimensionless coefficient, $\mathrm{C}$ was obtained as a function of the gas Weber number and Reynolds number assuming the surface area of a particle increases after deformation, while the volume remains constant.

Comparative analysis of well test results obtained from 105 gas wells between the new model, Turner's spherical model and Li's flat model reveal that droplet deformation plays an important role in the accuracy of prediction of critical flowrate for liquid loading. Error analysis carried out reveals that the new model predicted the onset of liquid loading in gas wells with the least error of $20 \%$, whereas Turner's model had $26 \%$ error and $\mathrm{Li}, 35 \%$ error.

Finally, the recommended applicable range of the new model is when the wellhead pressure is less than 500 psia and the liquid/gas ratios are in the range of 1-130 bbl/ MMscf, which is suggested by Turner et al. (1969) to ensure a mist flow in gas wells.

Open Access This article is distributed under the terms of the Creative Commons Attribution 4.0 International License (http://creativeco mmons.org/licenses/by/4.0/), which permits unrestricted use, distribution, and reproduction in any medium, provided you give appropriate credit to the original author(s) and the source, provide a link to the Creative Commons license, and indicate if changes were made.

\section{Appendix 1}

\section{Development of the critical velocity models}

\section{Turner model}

Since the liquid droplets are particles moving relative to a fluid in the gravitational field, particle mechanics may be employed to determine this minimum gas flow rate. A freely falling particle in a fluid medium will reach a terminal velocity, which is the maximum velocity it can attain under the influence of gravity alone, i.e. when the drag forces equal the accelerating forces. Terminal velocity is therefore a function of the size, shape and density of the particle and of the density and viscosity of the fluid medium. 
By transformation of coordinates, a drop of liquid being transported by moving gas stream becomes a free falling particle and the same general equations apply.

$V t=6.55 \sqrt{\frac{d\left(\rho_{1}-\rho_{\mathrm{g}}\right)}{\rho_{\mathrm{g}} C_{\mathrm{d}}} .}$

Turner determined that it is the antagonism of two pressures, the velocity pressure and the surface tension pressure that determines the maximum size a drop may attain. The ratio of these two pressures is the weber number. Hinze showed that if the weber number exceeded a critical value, a liquid drop would shatter. Weber number was found to be on the order of 20-30. If the larger of observed values is used, a relationship between the maximum drop diameter and the velocity of a liquid drop is obtained.

$d_{\mathrm{m}}=\frac{30 \sigma g_{\mathrm{c}}}{\rho_{\mathrm{g}} V_{\mathrm{t}}^{2}}$.

Substituting the maximum diameter expression into Eq. 28, the terminal velocity equation becomes

$V t=\frac{1.3 \sigma^{1 / 4}\left(\rho_{1}-\rho_{\mathrm{g}}\right)^{1 / 4}}{C_{\mathrm{d}}^{1 / 4} \rho_{\mathrm{g}}^{1 / 2}}$.

The drag coefficient is inflected by the drop shape and the drop Reynolds number, for spheres laboratory results shows that for a Reynolds number ranges of 1000 to 200,000 the drag coefficient is approximately constant and the drag coefficient of 0.44 was used resulting to

$V t=\frac{17.6 \sigma^{1 / 4}\left(\rho_{1}-\rho_{\mathrm{g}}\right)^{1 / 4}}{\rho_{\mathrm{g}}^{1 / 2}}$.

Converting the surface tension from $1 \mathrm{lbf} / \mathrm{ft}$ to 0.00006852 dyne/cm equation becomes

$V t=\frac{1.593 \sigma^{1 / 4}\left(\rho_{1}-\rho_{\mathrm{g}}\right)^{1 / 4}}{\rho_{\mathrm{g}}^{1 / 2}}$.

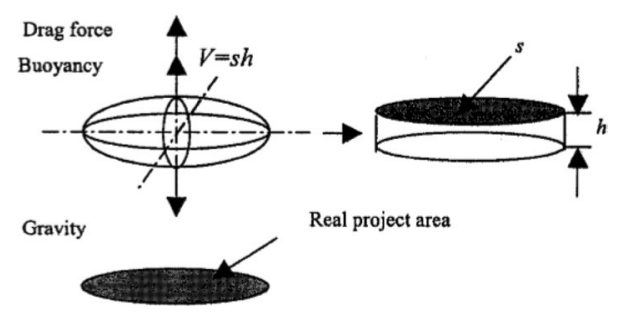

Fig. 16 Buoyancy, drag and gravity forces acting on a liquid droplet (Li et al. 2001)

\section{Li's model}

$\mathrm{Li}$ argued that a pressure difference exists between the fore and aft portion of a free falling droplet. The droplet is thus deformed, under the applied forces, from a sphere to a convex beam shown in Fig. 16 above.

Equating the gravity of a liquid droplet to the buoyancy and drag force, we obtain (in SI units)

$\rho_{1} g V=\rho_{\mathrm{g}} g V+1 / 2 \rho_{\mathrm{g}} v^{2} s C_{\mathrm{d}}$.

As the droplets fall relative to the gas stream velocity, the pressure difference existing between the fore and aft portions, by Bernoulli, is expressed as

$\Delta p=\frac{10^{-3} \rho_{\mathrm{g}} v^{2}}{2}$.

The condition for the balance of pressure and interfacial tension force is

$\left(\frac{\Delta p}{10^{-3}}\right) s \Delta h+\sigma \Delta s=0$.

For a constant volume of the droplet, the following condition must be satisfied:

$\mathrm{V}=\mathrm{sh}=$ constant

From equation A8, we obtain

$\frac{\Delta p s}{10^{-3} \sigma}=\frac{\Delta s}{\Delta h}$.

From Eq. 36, we have

$\frac{\Delta s}{\Delta h}=-\frac{V}{h^{2}}=-\frac{s h}{h^{2}}=-\frac{s}{h}$

By combining Eqs. 38 and 37, we calculate the thickness of the droplet as

$h=\frac{10^{-3} \sigma}{\Delta p}$

Substituting $\Delta p$ from Eqs. 34 into 39, we have

$h=\frac{2 \sigma}{\rho_{\mathrm{g}} v^{2}}$.

Hence, $s$ is estimated to be

$s=\frac{\rho_{\mathrm{g}} v^{2} V}{2 \sigma}$.

Substituting Eqs. 41 into 33 and solving for $v=v_{\mathrm{c}}$,

$v_{\mathrm{c}}=v=\sqrt[4]{\frac{4\left(\rho_{1}-\rho_{\mathrm{g}}\right) g \sigma}{\rho_{\mathrm{g}}^{2} C_{\mathrm{d}}}}$. 
For a typical field condition, the particle's Reynolds number ranges from $10^{4}$.

To $10^{5}$ and the drag coefficient $\left(C_{\mathrm{d}}\right)$ is close to 1.0 for the shape considered. Hence, we have

$v_{\mathrm{c}}=2.5 \frac{\sigma^{1 / 4}\left(\rho_{1}-\rho_{\mathrm{g}}\right)^{1 / 4}}{\rho_{\mathrm{g}}^{1 / 2}}$.
When converted to field units, we have

$v_{\mathrm{c}}=0.7241 \frac{\sigma^{1 / 4}\left(\rho_{1}-\rho_{\mathrm{g}}\right)^{1 / 4}}{\rho_{\mathrm{g}}^{1 / 2}}$.

\section{Appendix 2}

\begin{tabular}{|c|c|c|c|c|c|}
\hline \multicolumn{2}{|l|}{ LI's calculated } & \multicolumn{2}{|c|}{ Turner's calculated } & \multicolumn{2}{|l|}{ New model } \\
\hline $\begin{array}{l}\text { Critical } \\
\text { velocity (ft/s) }\end{array}$ & $\begin{array}{l}\text { Critical flow } \\
\text { rate (mcf/days) }\end{array}$ & $\begin{array}{l}\text { Critical } \\
\text { velocity (ft/s) }\end{array}$ & $\begin{array}{l}\text { Critical flow rate } \\
\text { (mcf/days) }\end{array}$ & $\begin{array}{l}\text { Critical } \\
\text { velocity (ft/s) }\end{array}$ & $\begin{array}{l}\text { Critical flow rate } \\
\text { (mcf/days) }\end{array}$ \\
\hline 7.421352494 & 699.4091215 & 16.32677051 & 1538.680749 & 27.56470916 & 2597.77568 \\
\hline 6.396371673 & 359.6368142 & 14.07184101 & 791.1910578 & 23.75768096 & 1335.778646 \\
\hline 4.131293989 & 2118.908919 & 9.088732668 & 4661.541097 & 15.34463124 & 7870.143366 \\
\hline 3.541108845 & 2462.936944 & 7.790341651 & 5418.39325 & 13.15253999 & 9147.947173 \\
\hline 3.386080896 & 2572.339805 & 7.449284445 & 5659.076522 & 12.57672846 & 9554.29602 \\
\hline 3.291364351 & 2644.010978 & 7.240910662 & 5816.751123 & 12.22492816 & 9820.500199 \\
\hline 3.234436286 & 332.9551895 & 7.115670493 & 732.4922205 & 12.01348348 & 1236.676599 \\
\hline 4.715188246 & 202.0876575 & 10.3732839 & 444.5872647 & 17.5133566 & 750.6027384 \\
\hline 4.059829716 & 1265.103589 & 8.93151324 & 2783.192953 & 15.07919553 & 4698.902595 \\
\hline 3.919333361 & 512.5407015 & 8.62242514 & 1127.575387 & 14.55735788 & 1903.700893 \\
\hline 3.758126787 & 533.7705151 & 8.267775131 & 1174.28039 & 13.95859744 & 1982.553587 \\
\hline 3.598854403 & 556.5083356 & 7.917380284 & 1224.302967 & 13.36702104 & 2067.007386 \\
\hline 3.053296867 & 651.0725861 & 6.717168773 & 1432.341706 & 11.34068759 & 2418.242025 \\
\hline 2.001478177 & 849.0393442 & 4.403196708 & 1867.863106 & 7.433977014 & 3153.53874 \\
\hline 1.943962951 & 871.8746529 & 4.276664799 & 1918.100155 & 7.220351467 & 3238.354633 \\
\hline 1.684472966 & 1417.688544 & 3.705793999 & 3118.87564 & 6.256542516 & 5265.640251 \\
\hline 1.491075008 & 1100.566301 & 3.280323834 & 2421.215463 & 5.538215437 & 4087.771065 \\
\hline 1.456080213 & 1122.729251 & 3.203336252 & 2469.973342 & 5.408236253 & 4170.089658 \\
\hline 1.455257267 & 290.9181632 & 3.201525792 & 640.0119237 & 5.405179628 & 1080.540854 \\
\hline 1.400981857 & 300.2324567 & 3.082121389 & 660.5031122 & 5.203587548 & 1115.136406 \\
\hline 1.365227426 & 778.9730088 & 3.00346263 & 1713.719104 & 5.070786893 & 2893.29532 \\
\hline 1.342980359 & 789.411588 & 2.954519697 & 1736.68369 & 4.988155872 & 2932.066743 \\
\hline 1.21719954 & 799.768578 & 2.677805368 & 1759.468782 & 4.520975299 & 2970.535124 \\
\hline 1.14102966 & 740.5246871 & 2.510233736 & 1629.133858 & 4.238061829 & 2750.488896 \\
\hline 1.120325183 & 750.4774926 & 2.464684459 & 1651.029755 & 4.161160365 & 2787.456038 \\
\hline 1.120009862 & 1127.752536 & 2.463990762 & 2481.024431 & 4.159989186 & 4188.747361 \\
\hline 1.092491886 & 510.4162589 & 2.403451973 & 1122.901672 & 4.057780724 & 1895.810197 \\
\hline 1.090396025 & 765.1843916 & 2.398841138 & 1683.384527 & 4.049996188 & 2842.08104 \\
\hline 1.081265155 & 514.1588825 & 2.378753475 & 1131.13534 & 4.016081913 & 1909.711211 \\
\hline 1.073654413 & 773.5731771 & 2.362010054 & 1701.839623 & 3.987813767 & 2873.23903 \\
\hline 0.821584786 & 910.0832924 & 1.807463838 & 2002.158106 & 3.051565831 & 3380.270819 \\
\hline 10.42094012 & 136.6487472 & 22.92578042 & 300.6234695 & 38.70590755 & 507.5467008 \\
\hline 5.307834134 & 254.6612526 & 11.67708849 & 560.2477219 & 19.71458765 & 945.8738646 \\
\hline 3.422057394 & 185.7565004 & 7.528431748 & 408.6591702 & 12.71035393 & 689.9448468 \\
\hline 4.524866689 & 297.7395319 & 9.954581738 & 655.0187465 & 16.80645602 & 1105.877077 \\
\hline 4.47176837 & 450.9070705 & 9.837766901 & 991.9831008 & 16.60923594 & 1674.778589 \\
\hline 2.641855551 & 356.5982659 & 5.812009242 & 784.5063356 & 9.812494416 & 1324.492739 \\
\hline 1.709903977 & 1399.141035 & 3.76174152 & 3078.071631 & 6.350999478 & 5196.750286 \\
\hline
\end{tabular}




\begin{tabular}{|c|c|c|c|c|c|}
\hline \multicolumn{2}{|l|}{ LI's calculated } & \multicolumn{2}{|c|}{ Turner's calculated } & \multicolumn{2}{|l|}{ New model } \\
\hline $\begin{array}{l}\text { Critical } \\
\text { velocity (ft/s) }\end{array}$ & $\begin{array}{l}\text { Critical flow } \\
\text { rate (mcf/days) }\end{array}$ & $\begin{array}{l}\text { Critical } \\
\text { velocity (ft/s) }\end{array}$ & $\begin{array}{l}\text { Critical flow rate } \\
\text { (mcf/days) }\end{array}$ & $\begin{array}{l}\text { Critical } \\
\text { velocity (ft/s) }\end{array}$ & $\begin{array}{l}\text { Critical flow rate } \\
\text { (mcf/days) }\end{array}$ \\
\hline 1.556999679 & 274.7512183 & 3.425356288 & 604.4450915 & 5.783075706 & 1020.492886 \\
\hline 1.499996768 & 1095.037664 & 3.299951458 & 2409.052616 & 5.571353022 & 4067.236365 \\
\hline 1.475833132 & 1110.124946 & 3.246792128 & 2442.244219 & 5.481603401 & 4123.274202 \\
\hline 1.403547149 & 299.7808064 & 3.087764962 & 659.509494 & 5.213115669 & 1113.458867 \\
\hline 1.369620827 & 776.9387388 & 3.013127989 & 1709.243766 & 5.087105051 & 2885.739546 \\
\hline 1.348429142 & 434.714034 & 2.966506868 & 956.3588679 & 5.008393976 & 1614.633711 \\
\hline 1.34746222 & 787.2900433 & 2.964379665 & 1732.01635 & 5.004802591 & 2924.186809 \\
\hline 1.135442959 & 743.1923023 & 2.497943148 & 1635.002538 & 4.217311462 & 2760.397068 \\
\hline 1.129647046 & 1120.7564 & 2.485192299 & 2465.633124 & 4.19578403 & 4162.762009 \\
\hline 1.127202887 & 1122.525143 & 2.479815217 & 2469.524309 & 4.186705829 & 4169.331549 \\
\hline 1.121590491 & 749.8640298 & 2.467468101 & 1649.680154 & 4.165860025 & 2785.177488 \\
\hline 1.08818154 & 511.8490824 & 2.393969333 & 1126.053844 & 4.041771052 & 1901.132052 \\
\hline 1.076379387 & 772.1999559 & 2.36800492 & 1698.818574 & 3.997934981 & 2868.138553 \\
\hline 1.060167742 & 521.2849112 & 2.332339749 & 1146.812407 & 3.937720986 & 1936.179016 \\
\hline 0.828289561 & 906.3740504 & 1.822214156 & 1993.997876 & 3.076468996 & 3366.493791 \\
\hline 2.069910537 & 823.3000487 & 4.553746009 & 1811.237367 & 7.688151451 & 3057.936733 \\
\hline 1.943055426 & 317.051904 & 4.274668269 & 697.5054317 & 7.216980699 & 1177.607927 \\
\hline 1.756986123 & 347.0319721 & 3.865320942 & 763.4607535 & 6.525874028 & 1288.961195 \\
\hline 2.550365894 & 396.0331763 & 5.610734525 & 871.2620492 & 9.472679569 & 1470.963592 \\
\hline 1.729666199 & 1385.031745 & 3.805217863 & 3047.031583 & 6.424401181 & 5144.34495 \\
\hline 2.488292397 & 405.1319773 & 5.474174545 & 891.2791601 & 9.242123494 & 1504.758753 \\
\hline 1.678272973 & 257.464428 & 3.692154187 & 566.4146304 & 6.233514235 & 956.2855403 \\
\hline 1.630809828 & 370.5014663 & 3.587736578 & 815.0929925 & 6.057224563 & 1376.132608 \\
\hline 1.599159534 & 376.8453131 & 3.518106805 & 829.0492801 & 5.939667668 & 1399.695199 \\
\hline 1.584225405 & 379.9067787 & 3.485252133 & 835.7844198 & 5.884198678 & 1411.066227 \\
\hline 1.574311494 & 381.9637827 & 3.463441805 & 840.3097719 & 5.847376003 & 1418.706441 \\
\hline 2.279657719 & 570.3090674 & 5.015184016 & 1254.664196 & 8.467203527 & 2118.266662 \\
\hline 2.276833029 & 439.3267218 & 5.008969777 & 966.5066536 & 8.456711942 & 1631.766356 \\
\hline 1.535862442 & 390.1324084 & 3.378854952 & 858.2805229 & 5.704566866 & 1449.046705 \\
\hline 1.519721278 & 393.6544503 & 3.343344836 & 866.0289177 & 5.644614654 & 1462.128425 \\
\hline 1.516458703 & 394.3731698 & 3.336167261 & 867.6100809 & 5.632496656 & 1464.797924 \\
\hline 1.511372749 & 1088.058447 & 3.324978303 & 2393.69853 & 5.613606187 & 4041.313852 \\
\hline 1.493290761 & 1099.188691 & 3.285198429 & 2418.18476 & 5.546445282 & 4082.654289 \\
\hline 1.471562939 & 732.1496788 & 3.237397821 & 1610.709071 & 5.465742864 & 2719.382077 \\
\hline 2.110573533 & 470.2398351 & 4.643203477 & 1034.514649 & 7.839183713 & 1746.585182 \\
\hline 1.413206941 & 418.3594754 & 3.109016236 & 920.3792905 & 5.248994485 & 1553.8889 \\
\hline 1.405757846 & 299.3925111 & 3.092628433 & 658.6552551 & 5.221326734 & 1112.016644 \\
\hline 1.392656745 & 325.8187734 & 3.063806374 & 716.7923022 & 5.172666058 & 1210.170213 \\
\hline 1.38625049 & 769.3187759 & 3.049712788 & 1692.480058 & 5.148871666 & 2857.437149 \\
\hline 2.046960152 & 483.1548332 & 4.503255796 & 1062.927288 & 7.602908137 & 1794.554627 \\
\hline 1.385191945 & 425.3032698 & 3.04738402 & 935.6554464 & 5.144939975 & 1579.679842 \\
\hline 1.374747968 & 774.5759431 & 3.024407558 & 1704.045681 & 5.106148501 & 2876.963548 \\
\hline 1.32615174 & 339.0168546 & 2.9174972 & 745.8277163 & 4.925650286 & 1259.191099 \\
\hline 1.323415957 & 441.3164356 & 2.911478551 & 970.8839689 & 4.915488919 & 1639.156637 \\
\hline 1.955275567 & 653.633251 & 4.301552242 & 1437.975099 & 7.262369277 & 2427.752957 \\
\hline 1.290926191 & 450.1400415 & 2.840001964 & 990.2956583 & 4.794814024 & 1671.929657 \\
\hline 1.282960346 & 452.3468883 & 2.822477325 & 995.1506602 & 4.765226936 & 1680.126423 \\
\hline 1.893367226 & 517.1644348 & 4.165355602 & 1137.747472 & 7.032426634 & 1920.874564 \\
\hline 1.890328167 & 517.8808064 & 4.158669756 & 1139.32347 & 7.021138828 & 1923.535343 \\
\hline
\end{tabular}

1.890328167 


\begin{tabular}{|c|c|c|c|c|c|}
\hline \multicolumn{2}{|l|}{ LI's calculated } & \multicolumn{2}{|c|}{ Turner's calculated } & \multicolumn{2}{|l|}{ New model } \\
\hline $\begin{array}{l}\text { Critical } \\
\text { velocity (ft/s) }\end{array}$ & $\begin{array}{l}\text { Critical flow } \\
\text { rate (mcf/days) }\end{array}$ & $\begin{array}{l}\text { Critical } \\
\text { velocity (ft/s) }\end{array}$ & $\begin{array}{l}\text { Critical flow rate } \\
\text { (mcf/days) }\end{array}$ & $\begin{array}{l}\text { Critical } \\
\text { velocity }(\mathrm{ft} / \mathrm{s})\end{array}$ & $\begin{array}{l}\text { Critical flow rate } \\
\text { (mcf/days) }\end{array}$ \\
\hline 1.268325947 & 456.4463974 & 2.790282052 & 1004.169467 & 4.710871218 & 1695.352997 \\
\hline 1.257046614 & 353.6829155 & 2.765467832 & 778.0926451 & 4.668977031 & 1313.664418 \\
\hline 1.845859692 & 686.9283921 & 4.060840339 & 1511.223489 & 6.85597209 & 2551.419214 \\
\hline 1.226248479 & 360.5449216 & 2.697712783 & 793.1888691 & 4.554585259 & 1339.151578 \\
\hline 1.80973596 & 537.5436438 & 3.981369126 & 1182.581169 & 6.721799758 & 1996.567906 \\
\hline 1.208624311 & 804.1004949 & 2.658940101 & 1768.998879 & 4.489124812 & 2986.624918 \\
\hline 1.787904127 & 705.8110894 & 3.933339696 & 1552.764902 & 6.640711016 & 2621.554147 \\
\hline 1.175099571 & 724.545081 & 2.585186599 & 1593.979166 & 4.36460577 & 2691.13675 \\
\hline 1.162399661 & 730.4436077 & 2.557247147 & 1606.955762 & 4.317435212 & 2713.045314 \\
\hline 1.105630712 & 506.0805299 & 2.432357028 & 1113.363188 & 4.106581521 & 1879.706244 \\
\hline 1.10253258 & 507.0985587 & 2.425541224 & 1115.602823 & 4.095074307 & 1883.487451 \\
\hline 1.100054031 & 507.9149264 & 2.420088484 & 1117.398809 & 4.085868371 & 1886.519639 \\
\hline 1.080199508 & 770.279937 & 2.376409082 & 1694.594586 & 4.012123842 & 2861.007135 \\
\hline 1.074300103 & 516.4981552 & 2.363430555 & 1136.281675 & 3.990212017 & 1918.399839 \\
\hline 1.474301242 & 825.382891 & 3.243422012 & 1815.819563 & 5.475913587 & 3065.672916 \\
\hline 1.451895651 & 835.1698762 & 3.19413033 & 1837.35066 & 5.39269377 & 3102.024161 \\
\hline 1.437724503 & 841.4514938 & 3.162954197 & 1851.170045 & 5.340058679 & 3125.355617 \\
\hline 1.426234667 & 846.5968816 & 3.137676874 & 1862.489756 & 5.297382631 & 3144.46684 \\
\hline 0.843677721 & 897.8268281 & 1.856067683 & 1975.194223 & 3.133624365 & 3334.747328 \\
\hline
\end{tabular}

\section{Appendix 3}

\section{Turner's data}

\begin{tabular}{|c|c|c|c|c|c|c|c|c|c|}
\hline $\begin{array}{l}\text { Producing } \\
\text { depth (ft) }\end{array}$ & $\begin{array}{l}\text { Wellhead } \\
\text { pressure } \\
\text { (psi) }\end{array}$ & $\begin{array}{l}\text { Condensate } \\
\text { gravity } \\
\text { (API) }\end{array}$ & $\begin{array}{l}\text { Conden- } \\
\text { sate make } \\
\text { (bbl/MM) }\end{array}$ & $\begin{array}{l}\text { Water make } \\
\text { (bbl/MM) }\end{array}$ & $\begin{array}{l}\text { Tubing ID } \\
\text { (in.) }\end{array}$ & $\begin{array}{l}\text { Tubing OD } \\
\text { (in.) }\end{array}$ & $\begin{array}{l}\text { Casing ID } \\
\text { (in.) }\end{array}$ & $\begin{array}{l}\text { Test flow rate } \\
\text { (Mcf/D) }\end{array}$ & $\begin{array}{l}\text { Well status dur- } \\
\text { ing test }\end{array}$ \\
\hline 6529 & 108 & 64.3 & 9.6 & 12.4 & 2.041 & & & 568 & Near L.U \\
\hline 2250 & 210 & 0 & 0 & 24 & & 2.375 & 6.276 & 470 & Loaded up \\
\hline 3077 & 280 & 0 & 0 & 28 & & 2.375 & 4.974 & 500 & Loaded up \\
\hline 3278 & 315 & 50 & 10 & 0 & 7.386 & & & 5740 & Loaded up \\
\hline 6739 & 400 & & 0 & 18 & 1.995 & & & 417 & Near L.U \\
\hline 3278 & 422 & 50 & 10 & 0 & 7.386 & & & 3890 & Loaded up \\
\hline 6770 & 450 & 61 & 11.3 & 0 & 1.995 & & & 442 & Near L.U \\
\hline 3278 & 459 & 50 & 10 & 0 & 7.386 & & & 2780 & Loaded up \\
\hline 3278 & 484 & 50 & 10 & 0 & 7.386 & & & 1638 & Loaded up \\
\hline 5080 & 500 & 50 & 14 & 0 & & 2.375 & 4.974 & 400 & Loaded up \\
\hline 7200 & 500 & 0 & 0 & 5 & & 2.375 & 4.052 & 800 & Loaded up \\
\hline 6700 & 540 & 70.8 & 10.5 & 10.5 & 1.995 & & & 712 & Near L.U \\
\hline 7531 & 552 & 54.9 & 25.1 & 22.3 & 2.441 & & & 1607 & Near L.U \\
\hline 6776 & 660 & 0 & 0 & 3.5 & & 2.375 & 6.276 & 4300 & Loaded up \\
\hline 7531 & 704 & 54.9 & 31.6 & 40.8 & 2.441 & & & 1313 & Loaded up \\
\hline 6404 & 725 & 63.8 & 6 & 0 & 2.441 & & & 775 & Near L.U \\
\hline 7531 & 760 & 54.9 & 46.1 & 45.1 & 2.441 & & & 1247 & Loaded up \\
\hline 7531 & 822 & 54.9 & 26.7 & 26.3 & 2.441 & & & 1356 & Loaded up \\
\hline 7531 & 1102 & 54.9 & 26.1 & 23.8 & 2.441 & & & 1365 & Loaded up \\
\hline
\end{tabular}




\begin{tabular}{|c|c|c|c|c|c|c|c|c|c|}
\hline $\begin{array}{l}\text { Producing } \\
\text { depth (ft) }\end{array}$ & $\begin{array}{l}\text { Wellhead } \\
\text { pressure } \\
\text { (psi) }\end{array}$ & $\begin{array}{l}\text { Condensate } \\
\text { gravity } \\
\text { (API) }\end{array}$ & $\begin{array}{l}\text { Conden- } \\
\text { sate make } \\
\text { (bbl/MM) }\end{array}$ & $\begin{array}{l}\text { Water make } \\
\text { (bbl/MM) }\end{array}$ & $\begin{array}{l}\text { Tubing ID } \\
\text { (in.) }\end{array}$ & $\begin{array}{l}\text { Tubing OD } \\
\text { (in.) }\end{array}$ & $\begin{array}{l}\text { Casing ID } \\
\text { (in.) }\end{array}$ & $\begin{array}{l}\text { Test flow rate } \\
(\mathrm{Mcf} / \mathrm{D})\end{array}$ & $\begin{array}{l}\text { Well status dur- } \\
\text { ing test }\end{array}$ \\
\hline 6180 & 1117 & 67 & 10.3 & 0 & & 2.875 & 6.184 & 5513 & Unloaded \\
\hline 6180 & 1184 & 67 & 10.3 & 0 & & 2.875 & 6.184 & 4843 & Loaded up \\
\hline 6180 & 1245 & 67 & 10.3 & 0 & & 2.875 & 6.184 & 4441 & Loaded up \\
\hline 5294 & 1246 & 71 & 0.9 & 0 & 1.995 & & & 2965 & Unloaded \\
\hline 5294 & 1480 & 71 & 0.9 & 0 & 1.995 & & & 2473 & Unloaded \\
\hline 7546 & 1509 & 52.2 & 4.1 & 0.6 & 1.75 & & & 4485 & Unloaded \\
\hline 5515 & 1520 & 65 & 13.1 & 0 & 3.958 & & & 4150 & Unloaded \\
\hline 5515 & 1550 & 65 & 13.1 & 0 & 3.958 & & & 3551 & Questionable \\
\hline 7639 & 1575 & 53.5 & 3.3 & 1 & 1.75 & & & 4410 & Unloaded \\
\hline 5515 & 1590 & 65 & 13.1 & 0 & 3.958 & & & 3009 & Loaded up \\
\hline 6850 & 1600 & 65 & 26.7 & 0 & & 4.5 & 6.184 & 6423 & Unloaded \\
\hline 5234 & 1680 & 71.7 & 54.1 & 0 & 1.995 & & & 4439 & Unloaded \\
\hline 5294 & 1737 & 71 & 0.9 & 0 & 1.995 & & & 1712 & Unloaded \\
\hline 8162 & 1765 & 56.7 & 7.7 & 0 & 1.995 & & & 2949 & Unloaded \\
\hline 5234 & 1784 & 71.7 & 54.1 & 0 & 1.995 & & & 3460 & Unloaded \\
\hline 6850 & 1818 & 65 & 26.7 & 0 & & 4.5 & 6.184 & 4998 & Questionable \\
\hline 7346 & 1835 & 52.7 & 27.8 & 0.4 & 1.995 & & & 8672 & Unloaded \\
\hline 7546 & 1839 & 52.2 & 4.1 & 0.6 & 1.75 & & & 3742 & Unloaded \\
\hline 5234 & 1861 & 71.7 & 54.1 & 0 & 1.995 & & & 2502 & Unloaded \\
\hline 5234 & 1895 & 71.7 & 54.1 & 0 & 1.995 & & & 1797 & Unloaded \\
\hline 5294 & 1902 & 71 & 30.9 & 0 & 1.995 & & & 1138 & Unloaded \\
\hline 6031 & 1913 & 62.5 & 24.8 & 0 & & 2.875 & 6.184 & 9897 & Unloaded \\
\hline 6031 & 1938 & 62.5 & 24.8 & 0 & & 2.875 & 6.184 & 9039 & Questionable \\
\hline 5962 & 1953 & 65 & 31.8 & 0 & & 2.875 & 6.184 & 9289 & Unloaded \\
\hline 6031 & 1958 & 62.5 & 24.8 & 0 & & 2.875 & 6.184 & 8185 & Loaded up \\
\hline 5962 & 1993 & 65 & 31.8 & 0 & & 2.875 & 6.184 & 8210 & Questionable \\
\hline 5934 & 2003 & 70 & 3.7 & 0 & & 3.5 & 6.184 & 11,767 & Unloaded \\
\hline 5962 & 2040 & 65 & 31.8 & 0 & & 2.875 & 6.184 & 6702 & Loaded up \\
\hline 6850 & 2042 & 65 & 26.7 & 0 & & 4.5 & 6.184 & 4124 & Loaded up \\
\hline 7639 & 2104 & 53.5 & 3.3 & 1 & 1.75 & & & 3598 & Unloaded \\
\hline 8162 & 2149 & 56.7 & 7.7 & 0 & 1.995 & & & 2385 & Unloaded \\
\hline 5725 & 2169 & 70 & 2.5 & 0 & & 4.5 & 6.184 & 7504 & Unloaded \\
\hline 5725 & 2175 & 70 & 2.5 & 0 & & 4.5 & 6.184 & 6405 & Questionable \\
\hline 5725 & 2182 & 70 & 2.5 & 0 & & 4.5 & 6.184 & 5501 & Loaded up \\
\hline 7475 & 2205 & 52.4 & 3.4 & 0 & 1.75 & & & 6871 & Unloaded \\
\hline 5934 & 2223 & 70 & 3.7 & 0 & & 3.5 & 6.184 & 9860 & Unloaded \\
\hline 7546 & 2224 & 52.2 & 4.1 & 0.6 & 1.75 & & & 2910 & Unloaded \\
\hline 6995 & 2226 & 65 & 17.9 & 0 & 1.995 & & & 1959 & Unloaded \\
\hline 5906 & 2256 & 67.5 & 15.1 & 0 & & 3.5 & 6.184 & 9747 & Unloaded \\
\hline 5906 & 2271 & 67.5 & 15.1 & 0 & & 3.5 & 6.184 & 8406 & Questionable \\
\hline 5906 & 2284 & 67.5 & 15.1 & 0 & & 3.5 & 6.184 & 7109 & Loaded up \\
\hline 6995 & 2335 & 65 & 17.9 & 0 & 1.995 & & & 1116 & Questionable \\
\hline 5934 & 2338 & 70 & 3.7 & 0 & & 3.5 & 6.184 & 8057 & Questionable \\
\hline 5934 & 2352 & 70 & 3.7 & 0 & & 3.5 & 6.184 & 6361 & Loaded up \\
\hline 7475 & 2406 & 52.4 & 3.4 & 0 & 1.75 & & & 5820 & Unloaded \\
\hline 8162 & 2415 & 56.7 & 7.7 & 0 & 1.995 & & & 1804 & Unloaded \\
\hline 7346 & 2421 & 52.7 & 27.8 & 0.4 & 1.995 & & & 6654 & Unloaded \\
\hline 7753 & 2527 & 52.6 & 5.5 & 0 & 1.995 & & & 4471 & Unloaded \\
\hline 8162 & 2556 & 56.7 & 7.7 & 0 & 1.995 & & & 1550 & Unloaded \\
\hline
\end{tabular}




\begin{tabular}{|c|c|c|c|c|c|c|c|c|c|}
\hline $\begin{array}{l}\text { Producing } \\
\text { depth (ft) }\end{array}$ & $\begin{array}{l}\text { Wellhead } \\
\text { pressure } \\
\text { (psi) }\end{array}$ & $\begin{array}{l}\text { Condensate } \\
\text { gravity } \\
\text { (API) }\end{array}$ & $\begin{array}{l}\text { Conden- } \\
\text { sate make } \\
\text { (bbl/MM) }\end{array}$ & $\begin{array}{l}\text { Water make } \\
\text { (bbl/MM) }\end{array}$ & $\begin{array}{l}\text { Tubing ID } \\
\text { (in.) }\end{array}$ & $\begin{array}{l}\text { Tubing OD } \\
\text { (in.) }\end{array}$ & $\begin{array}{l}\text { Casing ID } \\
\text { (in.) }\end{array}$ & $\begin{array}{l}\text { Test flow rate } \\
(\mathrm{Mcf} / \mathrm{D})\end{array}$ & $\begin{array}{l}\text { Well status dur- } \\
\text { ing test }\end{array}$ \\
\hline 7546 & 2574 & 52.2 & 4.1 & 0.6 & 1.75 & & & 1943 & Unloaded \\
\hline 7639 & 2582 & 53.5 & 3.3 & 1 & 1.75 & & & 2423 & Unloaded \\
\hline 7753 & 2611 & 52.6 & 5.5 & 0 & 1.995 & & & 3436 & Unloaded \\
\hline 7475 & 2655 & 52.4 & 3.4 & 0 & 1.75 & & & 4140 & Unloaded \\
\hline 7346 & 2705 & 52.7 & 27.8 & 0.4 & 1.995 & & & 5136 & Unloaded \\
\hline 7475 & 2783 & 52.4 & 3.4 & 0 & 1.75 & & & 2939 & Unloaded \\
\hline 7639 & 2814 & 53.5 & 3.3 & 1 & 1.75 & & & 1596 & Unloaded \\
\hline 7810 & 2823 & 52.2 & 5 & 0 & & 2.375 & 4.974 & 3863 & Loaded up \\
\hline 7810 & 2862 & 52.2 & 5 & 0 & & 2.375 & 4.974 & 3024 & Unloaded \\
\hline 7346 & 2884 & 52.7 & 27.8 & 0.4 & 1.995 & & & 3917 & Unloaded \\
\hline 8840 & 3025 & 60 & 54.8 & 0 & 2.441 & & & 3517 & Unloaded \\
\hline 11,355 & 3092 & 55 & 117.6 & 0 & 2.441 & & & 3351 & Unloaded \\
\hline 8840 & 3212 & 60 & 54.8 & 0 & 2.441 & & & 2547 & Loaded up \\
\hline 11,355 & 3245 & 55 & 117.6 & 0 & 2.441 & & & 2503 & Questionable \\
\hline 11,416 & 3280 & 56.4 & 130.8 & 0 & 2.992 & & & 4095 & Questionable \\
\hline 11,416 & 3295 & 56.4 & 130.8 & 0 & 2.992 & & & 3264 & Questionable \\
\hline 11,417 & 3330 & 56.4 & 113.5 & 0 & 2.441 & & & 2915 & Questionable \\
\hline 11,355 & 3338 & 55 & 117.6 & 0 & 2.441 & & & 2261 & Loaded up \\
\hline 11,416 & 3340 & 56.4 & 130.8 & 0 & 2.992 & & & 2611 & Loaded up \\
\hline 11,200 & 3434 & 61 & 37.4 & 0 & 1.995 & & & 2926 & Unloaded \\
\hline 11,390 & 3455 & 55 & 104.3 & 0 & 1.995 & & & 2769 & Unloaded \\
\hline 11,426 & 3472 & 55 & 106.9 & 0 & 1.995 & & & 2572 & Unloaded \\
\hline 11,426 & 3525 & 55 & 106.9 & 0 & 1.995 & & & 1792 & Loaded up \\
\hline 11,417 & 3540 & 56.4 & 113.5 & 0 & 2.441 & & & 1814 & Loaded up \\
\hline 11,390 & 3556 & 55 & 104.3 & 0 & 1.995 & & & 2069 & Questionable \\
\hline 11,200 & 3607 & 61 & 37.4 & 0 & 1.995 & & & 1525 & Loaded up \\
\hline 8690 & 3615 & 60 & 68.3 & 0 & 2.441 & & & 3890 & Unloaded \\
\hline 8690 & 3644 & 60 & 68.3 & 0 & 2.441 & & & 3182 & Questionable \\
\hline 11,340 & 3660 & 58 & 36.8 & 0 & 1.995 & & & 3726 & Unloaded \\
\hline 8690 & 3665 & 60 & 68.3 & 0 & 2.441 & & & 2542 & Loaded up \\
\hline 11,340 & 3773 & 58 & 36.8 & 0 & 1.995 & & & 2494 & Questionable \\
\hline 8963 & 4575 & 43.9 & 7.5 & 1.4 & 1.995 & & & 7792 & Unloaded \\
\hline 8963 & 4786 & 43.9 & 7.5 & 1.4 & 1.995 & & & 6221 & Unloaded \\
\hline 8963 & 4931 & 43.9 & 7.5 & 1.4 & 1.995 & & & 4830 & Unloaded \\
\hline 8963 & 5056 & 43.9 & 7.5 & 1.4 & 1.995 & & & 3376 & Unloaded \\
\hline 11,850 & 7405 & 67.5 & 10.8 & 0 & 2.441 & & & 6946 & Unloaded \\
\hline 11,850 & 7950 & 67.5 & 10.8 & 0 & 2.441 & & & 4896 & Questionable \\
\hline 11,850 & 8215 & 67.5 & 10.8 & 0 & 2.441 & & & 3472 & Loaded up \\
\hline
\end{tabular}




\section{Appendix 4}

LOADCALC PROGRAM CODES

Sub program_code_for_LOADCALC_software()

'program codes for the welcome message

Dim yourMsg As String

yourMsg = "Welcome to the LOADCALC platform for predicting liquid loading in gas wells. Click OK to continue"

MsgBox yourMsg, vbOK

'program codes for the input section of the software

Dim prodCONFIG As String

prodCONFIG = InputBox("ENTER PRODUCTION CONFIGURATION, FOR TUBING PRODUCTION ENTER 'T', FOR ANNULAR PRODUCTION ENTER 'A'", "PRODUCTION CONFIGURATION", "Enter T or $\mathrm{A}^{\prime \prime}$ )

Range("d3").Value = prodCONFIG

TubingID = InputBox("ENTER THE TUBING INNER DIAMETER IN INCHES. CLICK OK TO CONTINUE", "TUBING INNER DIAMETER", "inches")

Range("d4").Value = TubingID

TubingOD = InputBox("ENTER THE TUBING OUTER DIAMETER IN INCHES. CLICK OK TO CONTINUE", "TUBING OUTER DIAMETR", "inches")

Range("d5").Value = TubingOD

CasingID = InputBox("ENTER THE CASING INNER DIAMETER IN INCHES. CLICK OK TO CONTINUE", "CASING INNER DIAMETER", "inches")

Range("d6").Value = CasingID

PRODUCINGDEPTH = InputBox("ENTER THE PRODUCING DEPTH IN FEET", "PRODUCING DEPTH", "feet")

Range("d7").Value = PRODUCINGDEPTH

WATERDENSITY = InputBox("ENTER THE WATER DENSITY IN LB/CUFT, IF WATER IS PRODUCED ALONG WITH THE GAS, ELSE CLICK OK TO CONTINUE", "WATER DENSITY", "0")

Range("d9").Value = WATERDENSITY

WATERGASINTERFACIALTENSION = InputBox("ENTER THE WATER GAS INTERFACIAL TENSION IN DYNES/CM, IF WATER IS PRODUCED ALONG WITH THE GAS, ELSE CLICK OK TO CONTINUE", "WATER GAS INTERFACIAL TENSION", "0")

Range("d10").Value = WATERGASINTERFACIALTENSION

CONDENSATEDENSITY = InputBox("ENTER THE CONDENSATE DENSITY IN LB/CUFT, IF CONDENSATE IS PRODUCED ALONG WITH THE GAS, ELSE CLICK OK TO CONTINUE", "CONDENSATE DENSITY", "0")

Range("D11").Value = CONDENSATEDENSITY

CONDENSATEGASINTERFACIALTENSION = InputBox("ENTER THE CONDENSATE GAS INTERFACIAL TENSION IN DYNES/CM, IF CONDENSATE IS PRODUCED ALONG WITH THE GAS, ELSE CLICK OK TO CONTINUE", "CONDENSATE GAS INTERFACIAL TENSION", "0")

Range("D12").Value = CONDENSATEGASINTERFACIALTENSION 
SPECIFICGRAVITYOFGAS = InputBox("ENTER THE GAS SPECIFIC GRAVITY", "GAS SPECIFIC GRAVITY", "S.G")

Range("D13").Value = SPECIFICGRAVITYOFGAS

WELLHEADPRESSURE = InputBox("ENTER WELL HEAD PRESSURE IN PSIA", "WELLHEAD PRESSURE", "psia")

Range("N2").Value = WELLHEADPRESSURE

WELLHEADTEMPERATURE = InputBox("ENTER WELL HEAD TEMPERATURE IN DEGREE RANKINE", "WELL HEAD TEMPERATURE", "rankine")

Range("n3").Value = WELLHEADTEMPERATURE

TESTFLOWRATE = InputBox("ENTER GAS WELL TEST FLOW RATE IN MCF/D", "TEST FLOW RATE", "MCF/D")

Range("n4").Value = TESTFLOWRATE

Range("D22").GoalSeek goal:=Range("D34"), changingcell:=Range("D20")

$\mathrm{Z}=$ Range("D21").Value

GASDENSITY $=(2.7 *$ SPECIFICGRAVITYOFGAS * WELLHEADPRESSURE $) /(\mathrm{Z} *$ WELLHEADTEMPERATURE)

Range("D14").Value = GASDENSITY

If WATERDENSITY $=0$ Then

VCRITL $=(0.7241 *($ CONDENSATEGASINTERFACIALTENSION $) \wedge 0.25 *($ CONDENSATEDENSITY $\left.-\operatorname{GASDENSITY}^{\wedge} 0.25\right) /(\mathrm{GASDENSITY})^{\wedge} 0.5$

VCRITT $=\left(1.593 *(\text { CONDENSATEGASINTERFACIALTENSION })^{\wedge} 0.25 *(\right.$ CONDENSATEDENSITY GASDENSITY $\left.)^{\wedge} 0.25 /(\text { GASDENSITY })^{\wedge} 0.5\right)$

VCRITNEW $=$ VCRITL $+2.261921523 *($ VCRITT - VCRITL $)$

End If

If WATERDENSITY $>0$ Then

VCRITL $=\left(0.7241 *(\text { WATERGASINTERFACIALTENSION })^{\wedge} 0.25 *(\right.$ WATERDENSITY -

GASDENSITY $\left.)^{\wedge} 0.25\right) /(\text { GASDENSITY })^{\wedge} 0.5$

VCRITT $=(1.593 *($ WATERGASINTERFACIALTENSION $) \wedge 0.25 *($ WATERDENSITY GASDENSITY $\left.)^{\wedge} 0.25 /(\text { GASDENSITY })^{\wedge} 0.5\right)$

VCRITNEW $=$ VCRITL $+2.261921523 *($ VCRITT - VCRITL $)$

End If

Range("n9").Value = VCRITNEW

If prodCONFIG = "T" Then

$\mathrm{PIE}=3.142$

$\mathrm{AREA}=\left(\mathrm{PIE} *(\text { TubingID } / 12)^{\wedge} 2\right) / 4$

QCRIT $=(3060 *$ WELLHEADPRESSURE * VCRITNEW * AREA $) /($ WELLHEADTEMPERATURE * Z)

End If 


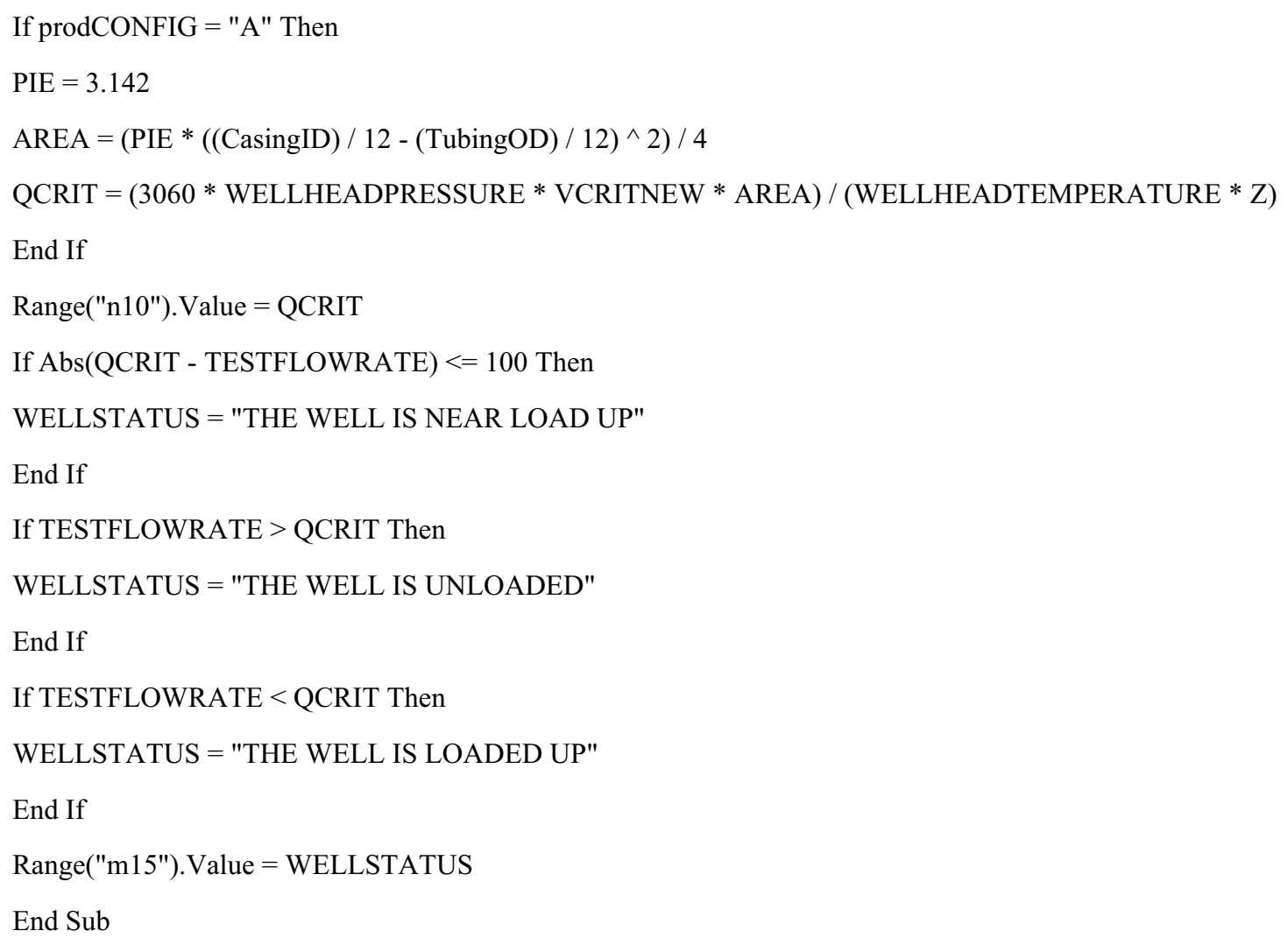

\section{Appendix 5}

\section{Derivation of deformation coefficient, $C$ for a droplet rising through gaseous medium}

Generally, small droplets maintain their spherical forms, but larger ones assume different shapes such as ellipsoid, oblate ellipsoid, spherical cap or saucer shape during the rise motion (Kelbaliyev and Ceylan 2007).

From Fig. 17, the characteristic dimension $(r)$ for the intermediate droplet can be estimated as

$r=R[1-\xi(\cos \theta)]$,

where $R$ is the equivalent radius (the radius of spherical droplet having the same volume as the intermediate droplet) and $\xi(\cos \theta)$ is a function representing the surface curvature. Taylor and Acrivos, 1964 represented the function $\xi(\cos \theta)$ by

$$
\begin{aligned}
\xi(\cos \theta)= & \lambda_{\mathrm{v}} \times \operatorname{Ac} \times \operatorname{Re}^{2} P_{2}(\cos \theta) \\
& -\frac{3}{70} \lambda_{v} \frac{11+10 \gamma}{1+\gamma} \operatorname{Ac}^{2} \operatorname{Re}^{3} P_{3}(\cos \theta)+\ldots
\end{aligned}
$$

where $\lambda_{v}=\varphi(\gamma)$.

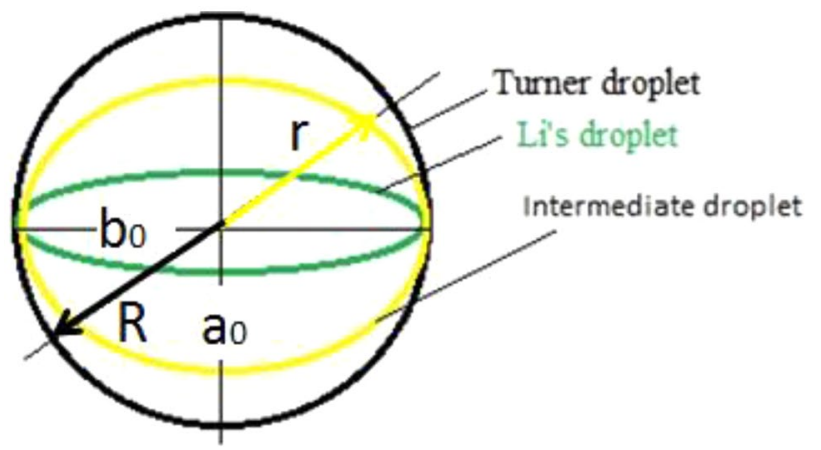

Fig. 17 Schematic representation of ellipsoidal bubble deformation and the characteristic dimensions

For the case of liquid drops in gaseous medium $\gamma \rightarrow \infty$ and then $\lambda_{v} \rightarrow 5 / 48$. According to the deformation and elasticity theory, the relation between the deformation and the variation in the dimension could be given as (Landau and Lifshitz 1953):

$\frac{1-\Delta C}{v_{\mathrm{p}} C-C_{\mathrm{s}}}=-z \Delta a$, 
where $v_{\mathrm{p}}$ is the volume of the particle, $a$ is the equivalent diameter of the particle, $C_{\mathrm{s}}$ is the stable deformation factor (maximum deformation or minimum aspect ratio), and $z$ is the compressibility factor.

Equation (47) can be modified as

$\lim _{\Delta a \rightarrow 0} \frac{\Delta C}{\Delta a}=\frac{\mathrm{d} C}{\mathrm{~d} a}=-v_{p} \times z\left(C-C_{\mathrm{s}}\right)$.

For spherical particles, it can be written as

$\frac{\mathrm{d} \chi}{\mathrm{d} a}=-\frac{\pi a^{3}}{6} z\left(C-C_{\mathrm{s}}\right)$,

$\left.C^{(a)}\right|_{a \rightarrow 0}=1$.

A solution to Eq. (49) can be given as

$C=C_{\mathrm{s}}+\left(1-C_{\mathrm{s}}\right) \times \exp \left(-\beta a^{4}\right)$,

where $\beta=1.475 \times 10^{-4} \cdot \mathrm{Mo}^{-1 / 5}, C_{\mathrm{s}}=0.5 \times \mathrm{Mo}^{1 / 8}$

However, the surface area of a particle increases after deformation, although the volume remains constant. If the drops or bubbles do not have sufficient surface energy, they undergo breakup after deformation. If the first term of Eq. (46) is sufficient to represent the surface curvature and if it is replaced by

$W e=\mathrm{Ac} \times R e^{2}$,

$P_{2}(\cos \theta)=0.5\left(3 \cos ^{2} \theta-1\right)$.

Then Eq. (46) can be written as

$r=R\left[1-\frac{\lambda_{\mathrm{v}}}{2} W e\left(3 \cos ^{2} \theta-1\right)\right]$.

If $\theta=0$ and $r=a_{0}$, then Eq. (54) can be rewritten as

$a_{0}=R\left(1-\lambda_{v} W e\right)$

and if $\theta=\pi / 2$ and $r=b_{0}$, then Eq. (54) can be written as

$b_{0}=R\left(1+\lambda_{\mathrm{v}} / 2^{W e}\right)$.

Based on these radii, the shape deformation is defined as

$C=\frac{a_{0}}{b_{0}}=\frac{R\left(1-\lambda_{\mathrm{v}} W e\right)}{R\left(1+\lambda_{\mathrm{v}} / 2 W e\right)}$.

Using the experimental data from Raymond and Rosant (2000), $\lambda_{\mathrm{v}}$ is estimated as

$\lambda_{\mathrm{v}}=\frac{1}{12}\left(1-\frac{3 W e}{25 R e}\right)$.

Weber's number can be obtained from
$W e=\frac{\rho \times v^{2} l}{\sigma}$,

whereas Reynolds number is obtained from

$R e=\frac{Q D_{\mathrm{H}}}{v A}$.

\section{References}

Acharya A, Mashelkar RA, Ulbrecht J (1977) Mechanics of bubble motion and deformation in non-newtonian media. Chem Eng Sci 32(8):863-872. https://doi.org/10.1016/0009-2509(77)80072-9

Adesina Fadairo DF, Oyewole, Falode O (2013) An improved predictive tool for liquid loading in a gas well. SPE 167552. https://doi. org/10.2118/167552-MS

Awolusi OS (2005) Resolving discrepancies in predicting critical rates in low pressure stripper gas wells. MS thesis, Texas Tech University, Lubbock, Texas (August 2005)

Coleman SB, Clay HB, McCurdy DG et al (1991) A new look at predicting gas-well load-up. J Pet Technol 43(3):329-333. https://doi. org/10.2118/20280-PA (SPE-20280-PA)

Guo B, Ghalambor A, Xu C (2006) A systematic approach to predicting liquid loading in gas wells. SPE Prod Oper 21(1):81-88. https:// doi.org/10.2118/94081-PA (SPE-94081-PA)

Guohua L, Shunli H (2012) A new model for the accurate prediction of liquid loading in low pressure gas wells. J Can Pet Technol 51(6):493-498. https://doi.org/10.2118/158385-PA

Hinze JO (1955) Fundamentals of the hydrodynamic mechanism of splitting in dispersion processes. AIChE J 1(3):289-295. https:// doi.org/10.1002/aic.690010303

Kelbaliyev G, Ceylan K (2007) Development of new empirical equations for estimation of drag coefficient, shape deformation, and rising velocity of gas bubbles or liquid drops. Chem Eng Commun 194(12):1623-1637

Landau LD, Liftshitz EM (1953) Mechanics of continuous medium. Nauka, Moscow

Li M, Li SL, Sun LT (2001) New view on continuous-removal liquids from gas wells. Paper SPE 75455, presented at the (2001) Permian basin oil and gas recovery conference, Midland, Texas, May 15-16. https://doi.org/10.2118/75455-PA

Nallaparaju YD, Pandit D (2012) Prediction of Liquid loading in gas wells. SPE 155356, presented at the SPE annual technical conference and exhibition, San Antonio Texas. https://doi. org/10.2118/155356-MS

Nosseir MA, Darwich TA, Sayyouh MH, El Sallaly M (2000) A new approach for accurate prediction of loading in gas wells under different flowing conditions. SPE Prod Fac 15(4):241-246. https ://doi.org/10.2118/120580-PA (SPE-66540-PA)

Raymond F, Rosant JM (2000) A numerical and experimental study of the terminal velocity and shape of bubbles in viscous liquids. Chem Eng Sci 55:943-955

Taylor T, Acrivos A (1964) On the deformation and drag of a falling drop at low Reynolds numbers. J Fluid Mech 18:466-476

Turner RG, Hubbard MG, Dukler AE (1969) Analysis and prediction of minimum low rate for the continuous removal of liquids from gas wells. J Petrol Technol. https://doi.org/10.2118/2198-PA (SPE-S2198-PA)

Wang YZ, Liu QW (2007) A new method to calculate the minimum critical liquids carrying flow rate for gas wells (in Chinese). J Pet Geol Oilfield Dev Daqing 26(6):82-85 
Wei N, Li YC, Li YQ (2007) Visual experimental research on gas well liquid loading (in Chinese). J Drill Prod Technol 30(3):43-45

Youngren GK, Acrivos A (1976) On the shape of a gas bubble in a viscous extensional flow. J Fluid Mech 76(3):433-442. https:// doi.org/10.1017/S0022112076000724

Zhou D, Yuan H (2009) New model for gas well loading prediction. Paper SPE 120580 presented at the SPE production and operations symposium, Oklahoma City, Oklahoma, USA, 4-8 April. https:// doi.org/10.2118/120580-MS

Publisher's Note Springer Nature remains neutral with regard to jurisdictional claims in published maps and institutional affiliations 